\title{
Magnetic and Electrical Properties of Nitrogen-Doped Multiwall Carbon Nanotubes Fabricated by a Modified Chemical Vapor Deposition Method
}

\author{
María Luisa García-Betancourt, ${ }^{1}$ Yadira Itzel Vega-Cantu, ${ }^{2}$ Sofía Magdalena Vega-Díaz, ${ }^{3}$ \\ Aarón Morelos-Gómez, ${ }^{4}$ Mauricio Terrones, ${ }^{4,5,6}$ and Emilio Muñoz-Sandoval ${ }^{1}$ \\ ${ }^{1}$ Advanced Materials Division, IPICYT, Camino a la Presa, San Jose 2055, 78216 San Luis Potosí, SLP, Mexico \\ ${ }^{2}$ Department of Chemistry, Federal University of Pernambuco, Cidade Universitária, 50670-901 Recife, PE, Brazil \\ ${ }^{3}$ CONACYT-Lectures, Technological Institute of Celaya, Avenida Tecnologico Esquina con Garcia Cubas S/N, \\ 38010 Celaya, GTO, Mexico \\ ${ }_{4}^{4}$ Institute for Carbon Science and Technology, Shinshu University, 4-17-1 Wakasato, Nagano City 380-8553, Japan \\ ${ }^{5}$ Department of Physics and Center for 2-Dimensional and Layered Materials, The Pennsylvania State University, \\ University Park, PA 16802-6300, USA \\ ${ }^{6}$ Department of Chemistry, Department of Materials Science and Engineering \& Materials Research Institute, The Pennsylvania State \\ University, University Park, PA 16802-6300, USA
}

Correspondence should be addressed to Emilio Muñoz-Sandoval; ems@ipicyt.edu.mx

Received 27 September 2014; Revised 13 January 2015; Accepted 19 January 2015

Academic Editor: Myoung-Woon Moon

Copyright (C) 2015 María Luisa García-Betancourt et al. This is an open access article distributed under the Creative Commons Attribution License, which permits unrestricted use, distribution, and reproduction in any medium, provided the original work is properly cited.

\begin{abstract}
Chemical vapor deposition (CVD) is a preferential method to fabricate carbon nanotubes (CNTs). Several changes have been proposed to obtain improved CNTs. In this work we have fabricated nitrogen-doped multiwall carbon nanotubes (N-MWCNTs) by means of a CVD which has been slightly modified. Such modification consists in changing the content of the by-product trap. Instead of acetone, we have half-filled the trap with an aqueous solution of $\mathrm{NaCl}(0-26.82$ wt.\%). Scanning electron microscope (SEM) characterization showed morphological changes depending upon concentration of $\mathrm{NaCl}$ included in the trap. Using high resolution transmission electron microscopy several shape changes on the catalyst nanoparticles were also observed. According to Raman spectroscopy results N-MWCNTs fabricated using pure distillate water exhibit better crystallinity. Resistivity measurements performed on different samples by physical properties measurement Evercool system (PPMS) showed metallic to semiconducting temperature dependent transitions when high content of $\mathrm{NaCl}$ is used. Results of magnetic properties show a ferromagnetic response to static magnetic fields and the coercive fields were very similar for all the studied cases. However, saturation magnetization is decreased if aqueous solution of $\mathrm{NaCl}$ is used in the trap.
\end{abstract}

\section{Introduction}

After the discovery, structural identification, and bulk production of carbon nanotubes (CNTs) the interest of researchers about these nanostructures increased exponentially, and the big quest for novel applications started [14]. Enormous and exhaustive work, carried out by several important groups, have exhibited their unique thermal, magnetic, mechanical, chemical, and electronic properties [5-7], thus leading to the design of new devices for biosensing, nanoprobing, spintronics, field emission, and other important applications [8-11].

One of the most important challenges in nanotube science nowadays is the control of the morphology because this is the route to control the physicochemical properties [10-12]. Depending on the desired applications, modifications in the chemical vapor deposition (CVD) method offer an optional approach to induce some important properties to carbon nanostructures, such as the introduction of water vapor together with the inert gas flow to grow very large carbon 
nanotubes $[13,14]$, or the modulation of the shape, size, and crystallinity of catalytic metallic nanoparticles determining the chiral-selective growth of CNTs [15]. In the case of the introduction of contaminants, some authors used alkali chlorides in order to deform the straight carbon nanofibers into helical structure or belts $[16,17]$; Lv and coworkers employed $\mathrm{Cl}$ as a cleaner of nanoparticles when introduced into the CVD, which evaporates during the process [18, 19]. In other cases it is desirable to have defects in carbon nanotubes such as nonhexagonal rings, dangling bonds, doping, non- $\mathrm{sp}^{2}$, and folding because they are the origin of producing many forms and new carbon architectures [1221] by adjusting some parameters in the chemical vapor deposition (CVD) method. For example, the introduction of sulfur in the atomizer solution allowed the synthesis of random 3D structures [22]. A two-step CVD was used for the production of three-dimensional networks [23] and long tipped CNTs [24]. Pressure and temperature fluctuations can produce branched junctions $[25,26]$. Currently, the versatility of CVD has been exploited widely, allowing modifications in their involved parameters in order to produce highly defective N-MWCNTs. Notwithstanding, research about this method continues increasing because the mechanism of growth of CNT remains unclear.

In the present work, following previous research [27, 28] we are proposing a simple modification of the CVD synthesis to alter the morphology and properties of $\mathrm{N}$ MWCNTs, also known as $\mathrm{CN}_{x}$; the modification consists in changing the solution of the by-product trap in the synthesis. We used deionized water and aqueous solutions of $\mathrm{NaCl}$ at different weight concentrations, low (1 wt.\%), halfsaturated (15.84 wt.\%), and saturated (26.92 wt.\%); instead of acetone which has been normally employed, we used water and aqueous solutions of $\mathrm{NaCl}$ at different weight concentrations. We also proposed the growth mechanism of these nanostructures.

\section{Materials and Methods}

Forests of nitrogen-doped carbon nanotubes (N-MWCNTs) were produced by a slightly modified CVD method using the one-furnace configuration with a by-product trap at the outlet of the quartz tube. The pyrolyzed solution containing $94 \%$ of benzylamine $\left(\mathrm{C}_{7} \mathrm{H}_{9} \mathrm{~N}\right.$, Sigma Aldrich), as a source of carbon and nitrogen, and $6 \%$ ferrocene $\left(\mathrm{FeCp}_{2}{ }^{-}\right.$, Sigma Aldrich) for the catalytic nanoparticles was prepared and placed in a reservoir plugged in to a pulse generator. The reaction was performed during $30 \mathrm{~min}$ and using a onefurnace system as is shown in Figure 1. The mixture solution of ferrocene and benzylamine was placed into the atomizer reservoir (see Figure 1). In order to obtain enough material to be characterized a small piece of $\mathrm{SiO}_{2} / \mathrm{Si}$ was placed inside the quartz tube at the middle of the furnace. In this zone, the temperature is stable $\left(850^{\circ} \mathrm{C} \pm 3^{\circ} \mathrm{C}\right)$. In a first experiment $200 \mathrm{~mL}$ of acetone was put inside the trap. We present some images of such CNT in Supplementary Information (see Figure S1 in Supplementary Material available online at http://dx.doi.org/10.1155/2015/587416). In a second experiment, we half-filled the trap with deionized water (Fermont) instead of acetone. For the following experiments, the density of deionized water was increased by adding $\mathrm{NaCl}$ at different weight concentrations (1wt.\%, 15.84 wt.\%, and $26.92 \mathrm{wt} . \%$ ). The obtained samples were called in agreement with the density of the liquid in the trap as $\mathrm{CN}_{x-1}$ for acetone (density $0.79 \mathrm{~g} / \mathrm{cm}^{2}$ ), $\mathrm{CN}_{x-2}$ for deionized water (density $1.00 \mathrm{~g} / \mathrm{cm}^{2}$ ), $\mathrm{CN}_{x-3}, \mathrm{CN}_{x-4}$, and $\mathrm{CN}_{x-5}$ for the cases of aqueous solutions of $\mathrm{NaCl}$ and densities of $1.01 \mathrm{~g} / \mathrm{cm}^{2}, 1.21 \mathrm{~g} / \mathrm{cm}^{2}$, and $1.56 \mathrm{~g} / \mathrm{cm}^{2}$, respectively. In all cases the total mixture poured in the trap was $200 \mathrm{~mL}$, which is equivalent to a half-filled trap. For the purpose of having an inert atmosphere inside of the quartz tube (see Figure 1), a constant argon flow rate of $2.5 \mathrm{~L} / \mathrm{min}$ was established. In all experiments, the temperature was $850^{\circ} \mathrm{C}$ inside of the furnace where the substrates were situated. The solution mixture was atomized from the solution container by an ultrasonic generator during $30 \mathrm{~min}$. In each case, the substrate was taken out for characterization using scanning electron microscopy (SEM-FEI XL 30 SFEG). In order to prepare the samples for high resolution transmission electron microscopy (HRTEM-FEI TECNAI F30) a small quantity was scraped from the substrates and incorporated into a vial with ethanol, ultrasonicated for 5 minutes and drop-cast on the grids. In the case of X-ray diffraction (RX Advance) characterization the whole substrate was used; the settings follow: $2 \theta$ from $10^{\circ}$ to $90^{\circ}$ and step size of 0.04 during 5 seconds. Raman characterization was performed using a laser of $514 \mathrm{~nm}$ in a Raman Renishaw Micro-Raman equipment. Thermogravimetric analysis was achieved using a TGAThermo Cahn, model Versa Therm apparatus. The magnetic and resistivity measurements were carried out in a physical properties measurement system (PPMS, Quantum Design). In order to verify the substance effect in the morphology and physical properties of N-MWCNTs we carried out additional experiments as following: (i) the trap was filled with $300 \mathrm{~mL}$ of mixture solution of benzylamine and ferrocene $(2.5 \%$ wt.\%); (ii) there was not any substance in the atomizer reservoir; (iii) several clean substrates were placed inside of quartz tube; (iv) the experimental setup was run normally. The resultant sample (substrate and CNT) from this experiment were characterized by SEM (Figure S4 of Supplementary Information) and analyzed in an optical emission spectrophotometer (OES) in order to measure ppm of $\mathrm{Na}$ or $\mathrm{Cl}$.

\section{Results}

Figure 2 exhibits SEM images of N-MWCNTs obtained from the different synthesis conditions described above. Figure 2(a) is SEM images of N-MWCNTs fabricated using acetone in the trap $\left(\mathrm{CN}_{x-1}\right.$ sample); such CNTs are vertically aligned and in general they present bamboo morphology [29, 30] with diameters around $50 \mathrm{~nm}$; sometimes it is possible to observe CNTs with smaller diameters enrolled to the thicker CNTs. In the case when the trap is half-filled with distilled water $\left(\mathrm{CN}_{x-2}\right.$ sample), the fabricated CNTs have larger diameters and present morphologies which are showed in Figure 2(b); some collapsed structures can be present (see inset). If an aqueous solution of $\mathrm{NaCl}$ is used in the trap an additional phenomena could be observed $\left(\mathrm{CN}_{x-3}\right.$ sample). In this case, sharp morphologies of N-MWCNTs were observed. 


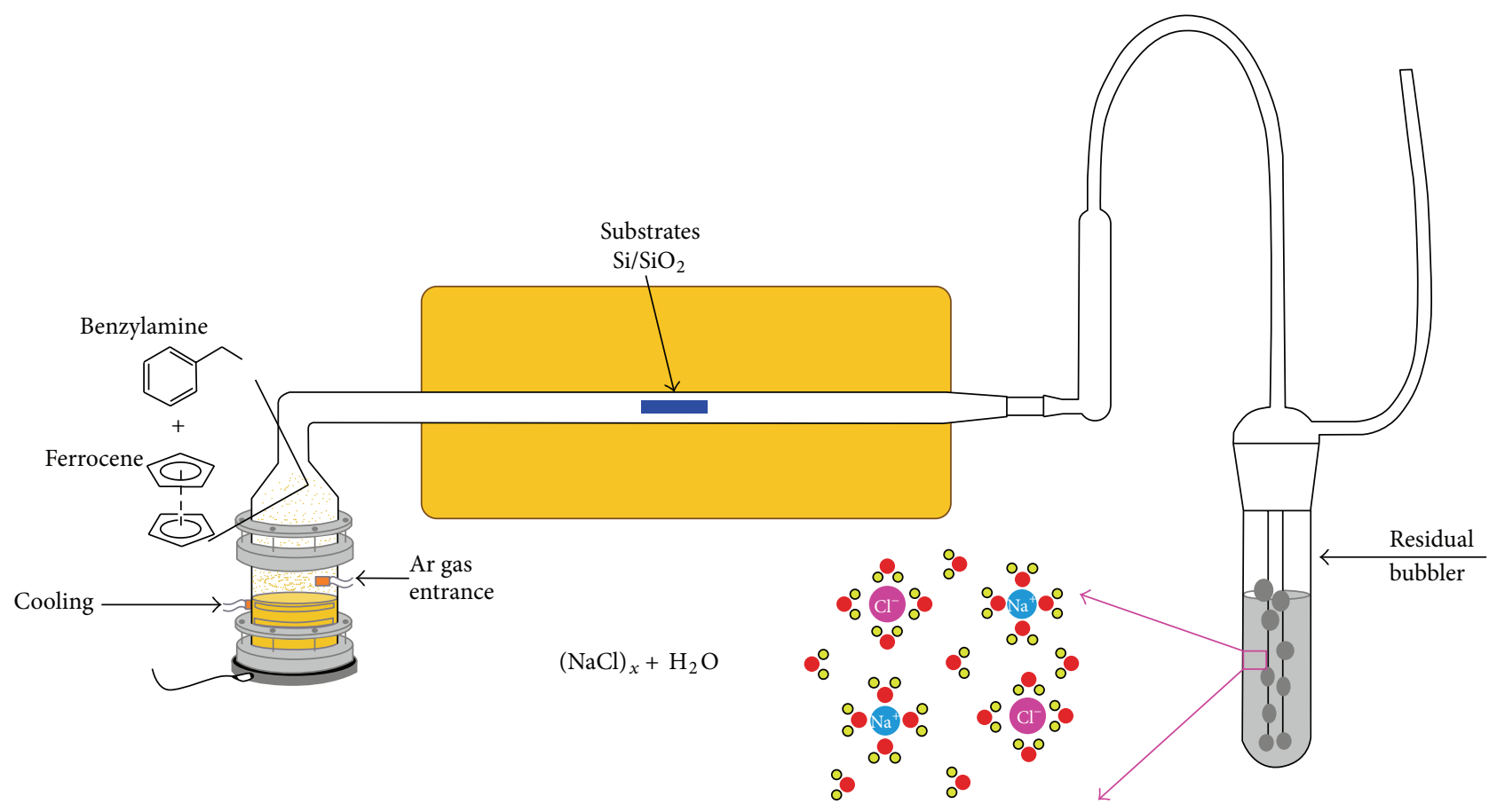

FIGURE 1: Typical CVD setup for carbon nanotubes synthesis using one furnace. Each component used for producing our samples is indicated in the figure. The size of the trap is only representative. The level used in the trap is an important parameter for all our experiments because they are determining the structure and physical properties of resultant N-MWCNTs nanotubes. The substrate is $10 \mathrm{~cm}$ long and was placed inside the quartz tube at the middle of the furnace $(20 \mathrm{~cm})$.

It seems that such morphologies are formed because the end compartments of the bamboo structure are damaged. Apparently, small nanoparticles play an important role to form sharp CNTs. Another well detectable defect mostly observed in the $\mathrm{CN}_{x-4}$ samples is nanoparticles attached to the external walls of N-MWCNTs known as "nanolumps" $[31,32]$. Such nanoparticles may abundantly appear forming "lumpy" nanostructures as is shown in Figure 2(d); Li and coworkers obtained lumpy CNT as a result of air-assisted synthesis [33]. It is probable that these lumps could catalyze thin N-MWCNTs forming the branch morphology [34]. More complex defects were detected in the sample $\mathrm{CN}_{x-5}$. Coalescence of N-MWCNTs and ruptures of thick CNTs with arms or branches were observed (Figure 2(e)). As can be seen at this figure very thin N-MWCNTs with few layers are emerging from such coalesced nanotubes. In Figure 2(f) the catalytic nanoparticles responsible for the growth of $\mathrm{CN}_{x-5}$ are shown. Notice the sharp nail structure as claws. This situation can be one of the main effects of putting saturated $\mathrm{NaCl}$ aqueous solution inside the trap.

Figure 3 displays representative TEM images of the different fabricated N-MWCNTs. Figure 3(a) contains a micrograph of the case $\mathrm{CN}_{x-2}$ (water), showing N-MWCNTs with diameters as small as $2 \mathrm{~nm}$ and as big as $60 \mathrm{~nm}$. Most of N-MWCNTs exhibited bamboo-type morphology, some of them with conical and other with cylindrical compartments. It is difficult to say how nitrogen is incorporated into the NMWCNTs without X-ray photoelectron spectroscopy (XPS) analysis of the samples. However, there are some studies showing that the shape of compartments can be associated with the type of nitrogen inclusion in the graphitic structure of CNT [35]. Both shapes of compartments are also observed in N-MWCNTs fabricated when acetone is used in the trap (see Figure S1, Supplementary Information). Figure 3(b) also exhibits representative TEM images of N-MWCNTs corresponding to the $\mathrm{CN}_{x-2}$ (water). Here, it is possible to observe a thin CNT with two collapsed sites and a CNT with lumps of different sizes (Figure 3(b)). In the case of aqueous solution with $\mathrm{NaCl} 1 \mathrm{wt} . \%$ (distilled water slightly altered with $\mathrm{NaCl}$ ) another morphology of N-MWCNTs is observed, namely, broken CNTs with a sharp end where an encapsulated conical-shape nanoparticle is observed (Figure 3(c)); for the case $\mathrm{CN}_{x-4}$ using aqueous solution of $\mathrm{NaCl} 15.84$ wt.\% (water with $\mathrm{NaCl}$ at half-saturation) the sample shows a lump attached to CNT (Figure 3(d)). The sample $\mathrm{CN}_{x-5}$, when the trap was filled with aqueous solution of $\mathrm{NaCl}$ at $26.92 \mathrm{wt} . \%$ (saturated water of $\mathrm{NaCl}$ ), exhibited complex morphologies as displayed in Figures 3(e) and 3(f). Apparently coaxial CNTs with large diameters and ruptures are formed in this case (Figure 3(e)). These CNTs can be coalesced with others to form the structure presented in the right part of Figure 3(e). In addition, it is probable to find multiterminal junctions containing different shapes and sized metallic nanoparticles (Figure 3(f)).

The diameter distribution corresponding to the different obtained N-MWCNTs samples is presented in Figure S5. The diameter distribution has a Gaussian-type shape in the case of $\mathrm{CN}_{x-1}$, which is the sample produced using a trap with acetone. In the case of $\mathrm{CN}_{x-2}$ and $\mathrm{CN}_{x-3}$ the respective diameter distribution curves exhibit bimodal behaviors. In 


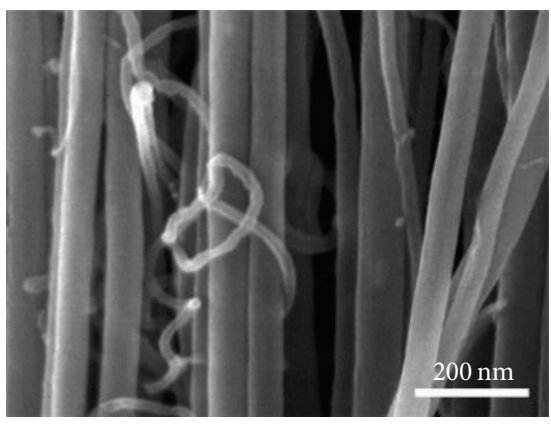

(a) $\mathrm{CN}_{x-1}$

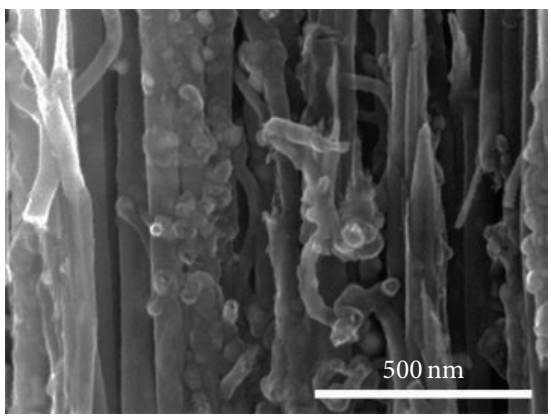

(d) $\mathrm{CN}_{x-4}$

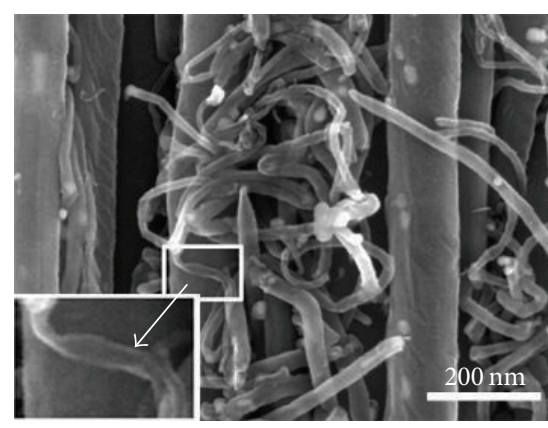

(b) $\mathrm{CN}_{x-2}$

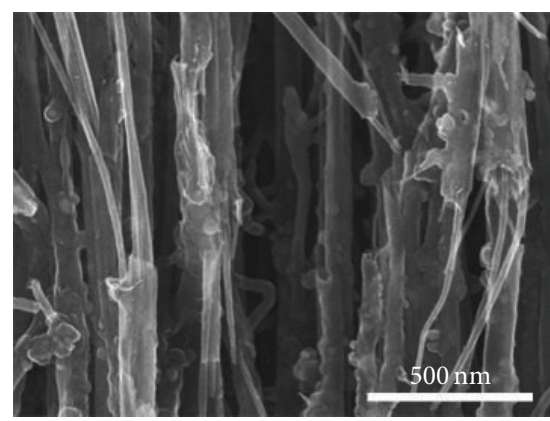

(e) $\mathrm{CN}_{x-5}$

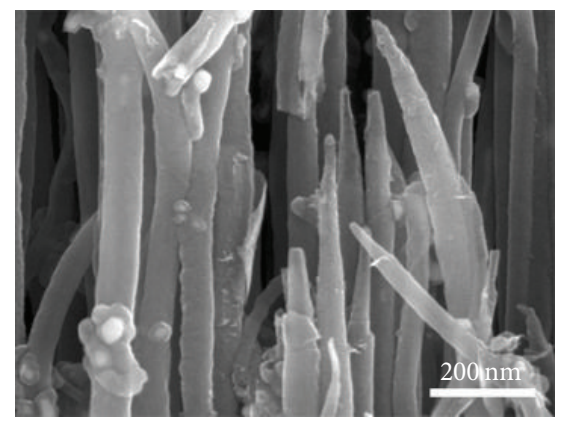

(c) $\mathrm{CN}_{x-3}$

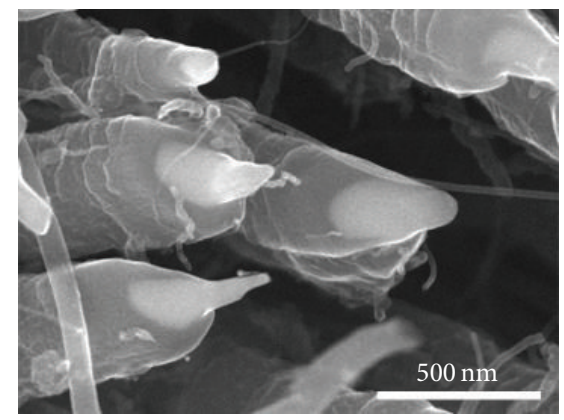

(f)

FIGURE 2: SEM images of the aligned N-MWCNTs grew over $\mathrm{Si} / \mathrm{SiO}_{2}$ substrates displaying the different morphologies observed in our samples: (a) typical morphology of N-MWCNTs produced with acetone in the trap $\left(\mathrm{CN}_{x-1}\right)$; (b) N-MWCNTs fabricated using deionized water in the trap $\left(\mathrm{CN}_{x-2}\right)$; (c) image showing tip morphology of N-MWCNTs formed when an aqueous solution of $\mathrm{NaCl}$ is used (1.0 wt.\% case; $\left.\mathrm{CN}_{x-3}\right)$; (d) image of N-MWCNTs in the case of $\mathrm{CN}_{x-4}$ case: here lumps are the main defects detected; (e) image of $\mathrm{CN}_{x-5}$ case (aqueous solution of $\mathrm{NaCl} 26.92$ wt.\%): complex structures are observed with very thin CNTs; (f) root part of $\mathrm{CN}_{x-5}$ : N-MWCNTs also fabricated with aqueous solution of $\mathrm{NaCl} 26.92 \mathrm{wt}$.\%, showing dramatic changes in the catalytic nanoparticles. More related SEM figures can be seen in SI (Figure S4).

the cases of $\mathrm{CN}_{x-4}$ and $\mathrm{CN}_{x-5}$ the diameter distributions are also bimodal however with lower pronounced differences. The average diameters for the different cases were $62 \pm 2 \mathrm{~nm}$, $47 \pm 3 \mathrm{~nm}, 61 \pm 2 \mathrm{~nm}, 36 \pm 2 \mathrm{~nm}$, and $37 \pm 2 \mathrm{~nm}$ for $\mathrm{CN}_{x-1}$, $\mathrm{CN}_{x-2}, \mathrm{CN}_{x-3}, \mathrm{CN}_{x-4}$, and $\mathrm{CN}_{x-5}$, respectively.

It is probable that the different CNT morphologies found in our samples could be attributed to the catalytic metallic nanoparticles. The final shape of these nanoparticles could give us information about the process involved in the growth of different N-MWCNTs observed. Figure 4 depicts TEM images of some encapsulated metallic nanoparticles found in distinct N-MWCNTs samples. Long nanowires with more than $500 \mathrm{~nm}$ length (Figure 4(a)) were observed in the samples $\mathrm{CN}_{x-2}$ and $\mathrm{CN}_{x-3}$ (low content of $\mathrm{NaCl}$ in the trap). Encapsulated nanoparticles with irregular morphologies distort the CNT structure (Figure 4(b)) or can form junctions (Figure 4(c)). These types of nanoparticles were observed in $\mathrm{CN}_{x-4}$ which were produced with a moderate quantity of aqueous solution $\mathrm{NaCl}$ in the trap. Very small encapsulated nanoparticles along the CNTs (internal multiparticles) were detected in N-MWCNTs fabricated with a saturated aqueous solution $\mathrm{NaCl}$ in the trap (Figure 4(d)). Also lumps encapsulating nanoparticles with oval morphology or nanoparticles incrusted in the wall could be found in this saturated case (Figures 4(e) and 4(f)). It seems that the inclusion of $\mathrm{NaCl}$ in the trap with water produces effects among the nanoparticles. However, it is not possible to be sure about that, unless more sophisticate experiments are performed to elucidate the real growth mechanism.

Figure 5 shows the X-ray diffractograms for all the samples obtained from the diverse situations. $\mathrm{CN}_{x-1}$ presents the two typical predominant phases characteristic of $\mathrm{N}$ MWCNTs fabricated with acetone in the trap, namely, $\mathrm{C}$ and $\mathrm{Fe}_{3} \mathrm{C}$; possibly $\alpha$-Fe phase is also present. Probably the most intense peak of (110) of $\alpha$-Fe around $45^{\circ}$ is spliced with the plane (103) of $\mathrm{Fe}_{3} \mathrm{C}$. The inclusion of distilled water inside of the trap $\left(\mathrm{CN}_{x-2}\right)$ changes the diffraction patterns and some peaks of $\mathrm{Fe}_{3} \mathrm{C}$ were relatively increased such as (112), (021), (200), and (120) planes for $2 \theta: 37.73^{\circ}, 38.03^{\circ}, 40.09^{\circ}$, and $41.28^{\circ}$, respectively; the peaks for the planes (140) and (313) at $78.27^{\circ}$ and $78.78^{\circ}$ present a relative higher intensity as well. Note that the $\mathrm{Fe}_{3} \mathrm{O}_{4}$ is clearly present in this case. For $\mathrm{CN}_{x-3}$, which is the case when the aqueous solution contains $1.0 \mathrm{wt} . \%$, the appearance of iron oxides (maghemite $\gamma$ - $\mathrm{Fe}_{2} \mathrm{O}_{3}$ and magnetite $\mathrm{Fe}_{3} \mathrm{O}_{4}$ ) in the samples is clearly seen in Figure 5 (green plot). However, if the percentage of $\mathrm{NaCl}$ is increased in the aqueous solution used in the trap, the intensities of peaks corresponding to iron oxides phase are reduced or in some cases they disappear. This situation could be due to the $\mathrm{Na}^{+}$and $\mathrm{Cl}^{-}$ions saturated in the water molecules, limiting 


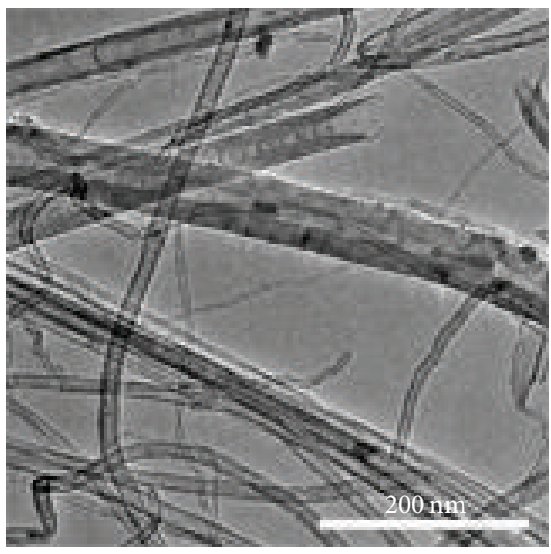

(a) $\mathrm{CN}_{x-2}$

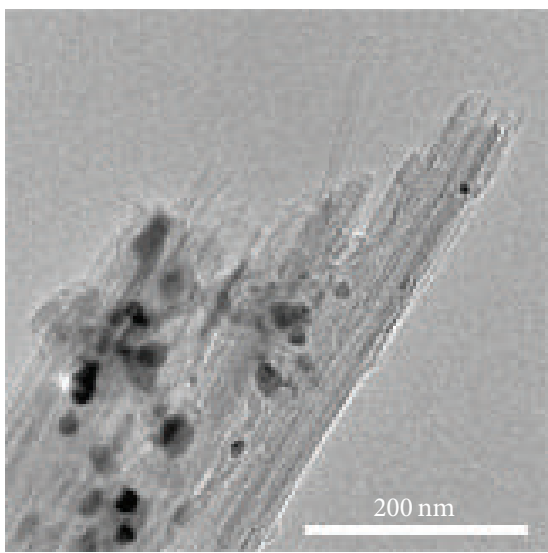

(d) $\mathrm{CN}_{x-4}$

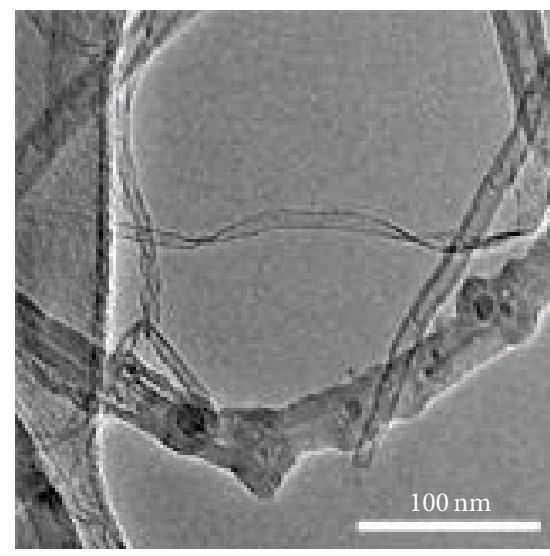

(b) $\mathrm{CN}_{x-2}$

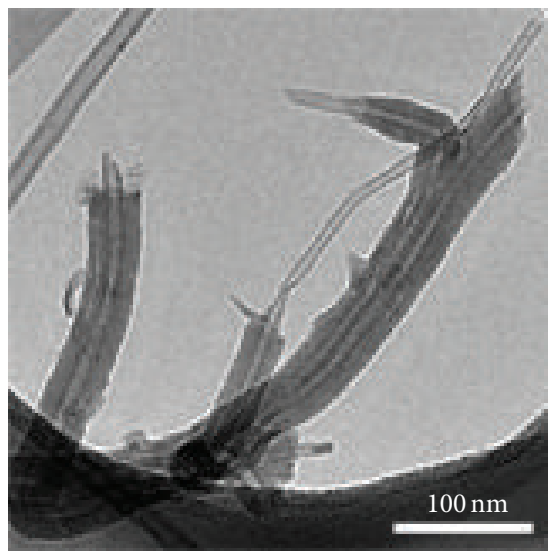

(e) $\mathrm{CN}_{x-5}$

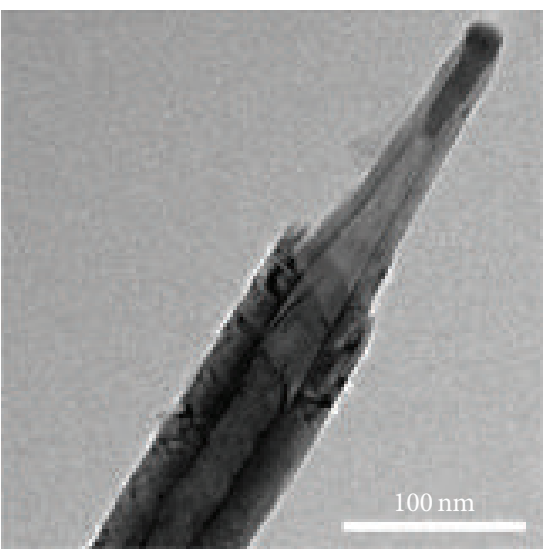

(c) $\mathrm{CN}_{x-3}$

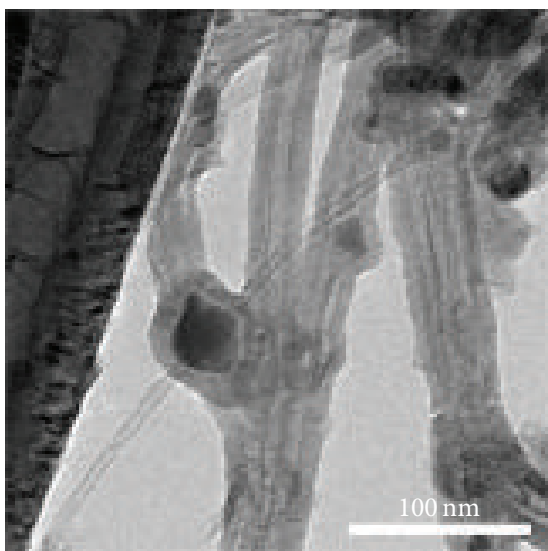

(f) $\mathrm{CN}_{x-5}$

FIGURE 3: TEM images displaying the representative morphologies of fabricated N-MWCNTs over $\mathrm{Si} / \mathrm{SiO}_{2}$ substrates using different aqueous solutions of $\mathrm{NaCl}$ in the trap, namely, (a) and (b) $\mathrm{CN}_{x-2}$; (c) $\mathrm{CN}_{x-3}$; (d) $\mathrm{CN}_{x-4}$; and (e) and (f) $\mathrm{CN}_{x-5}$.

the oxygen reflux entrance to the system. This could be the reason why the $\mathrm{X}$-ray diffractogram of $\mathrm{CN}_{x-1}$ is very similar to the respective $\mathrm{CN}_{x-5}$.

In order to analyze the thermal stability and reactivity of our N-MWCNTs we have carried out thermogravimetric analysis (TGA) under oxygen atmosphere. The samples were analyzed using a rate heating of $10 \mathrm{C} / \mathrm{min}$. Figure 6 shows the degradation curve for each sample, plotted as loss mass (\%) versus temperature. Al curves are similar with some differences related to the samples, such as the degradation temperature, obtained from the maximum value of the first loss mass derivative (see inferior inset at the left), calculated from the degradation plots. The maximum values of first loss mass derivative are plotted for each sample at the top inset at the right. As can be seen, the plot has in general a decreasing behavior as the weight percent of $\mathrm{NaCl}$ was increased, showing a maximum value of $458^{\circ} \mathrm{C}$ for $\mathrm{CN}_{x-2}$ (only water in the trap), revealing that this sample is the least reactive compared to the other cases. It seems that water in the trap produces CNTs more resistant to oxidation with fewer defects or nitrogen atoms in the walls. Possibly this result could be correlated with the fact that the compartments of $\mathrm{CN}_{x-2}$ are longer than the other cases (see Figure 4(b)). The decrease of degradation temperature in the samples $\mathrm{CN}_{x-3}, \mathrm{CN}_{x-4}$, and $\mathrm{CN}_{x-5}$ could be attributed to the introduction of additional defects to the graphitic surface of CNTs. The mass loss at lower temperatures could be imputed by the quantity of amorphous carbon in the sample. We observed that $\mathrm{CN}_{x-2}$ contains the higher percentage of amorphous carbon $(\sim 1.24 \%)$, higher than $\mathrm{CN}_{x-1}(\sim 1.04 \%)$ and $\mathrm{CN}_{x-3}, \mathrm{CN}_{x-4}$, and $\mathrm{CN}_{x-4}(0.62 \%$, no observable $\%, 0.85 \%$, resp.). The residual mass observed at the final degradation temperature corresponds to the iron oxide; the content was also different for each sample. $\mathrm{CN}_{x-1}$ exhibits the lowest residual mass (7.41\%), while for $\mathrm{CN}_{x-2}$ and $\mathrm{CN}_{x-3}$ the percentage is very similar (7.94\% and $8.08 \%$, resp.) and for $\mathrm{CN}_{x-4}$ and $\mathrm{CN}_{x-5}$ the percentage of residual was increasing ( $8.44 \%$ and $8.72 \%$, resp.). The reason for this increase can be associated with the agglomeration of metallic nanoparticles particles in the later cases, as was observed with the presence of nanolumps which are bigger for these cases.

For the purpose of studying the microstructure and crystalline order of our carbon nanotubes we performed Raman spectroscopy measurements. We used excitation energy of $514 \mathrm{~nm}$ over the samples of N-MWCNTs synthesized with the different liquids in the residual bubbler. The Raman spectra are presented in Figure 7(a), plotted between 100 and 


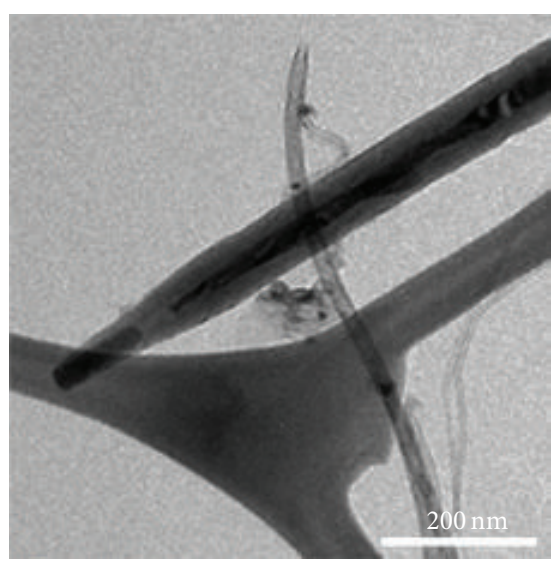

(a) $\mathrm{CN}_{x-3}$

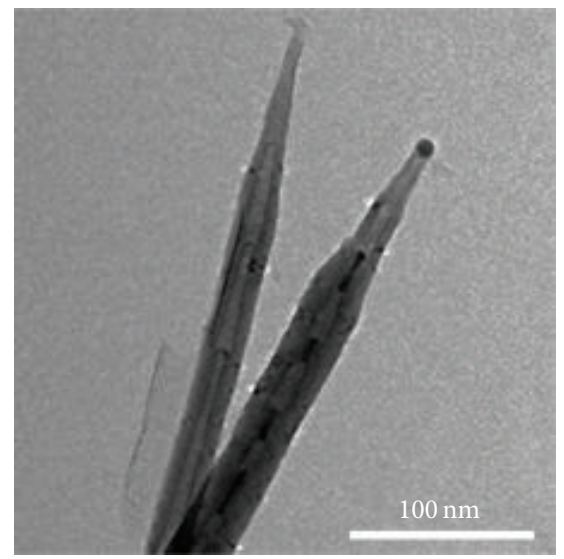

(d) $\mathrm{CN}_{x-5}$

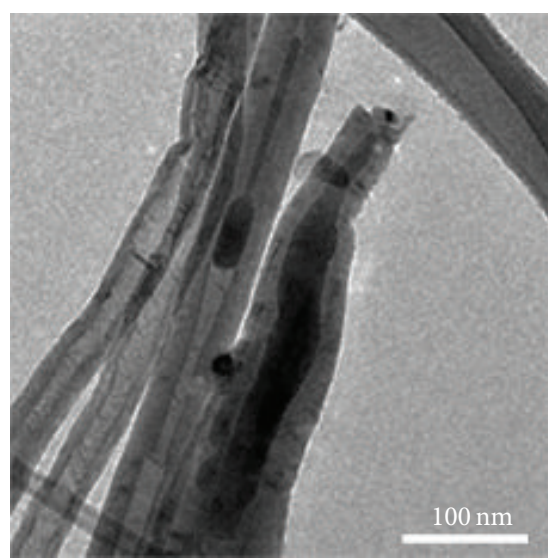

(b) $\mathrm{CN}_{x-4}$

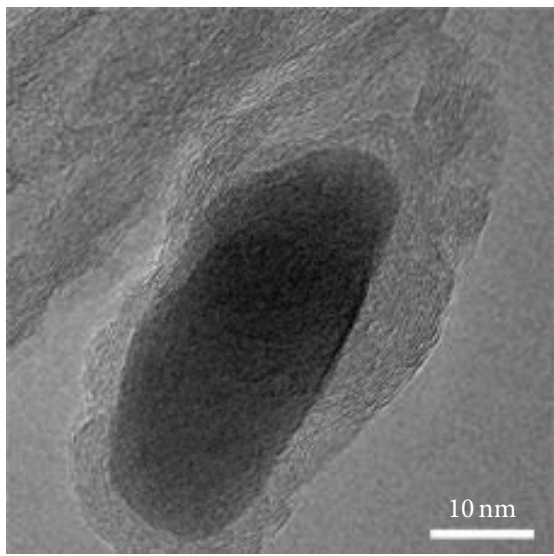

(e) $\mathrm{CN}_{x-5}$

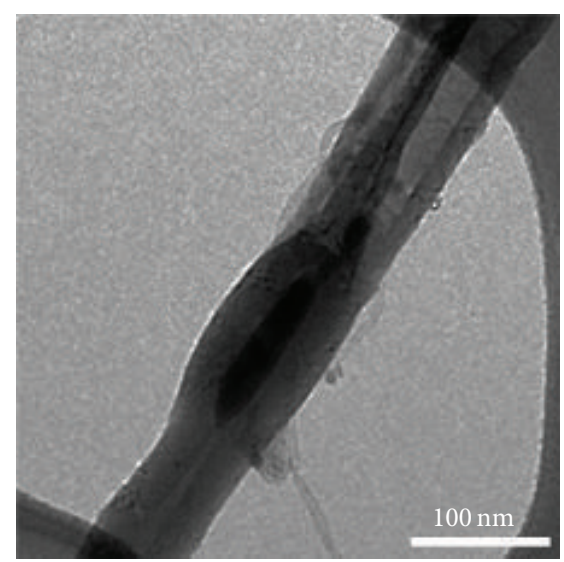

(c) $\mathrm{CN}_{x-4}$

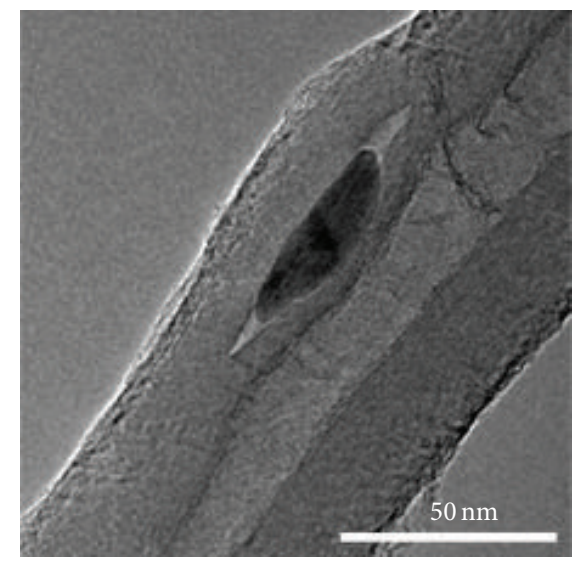

(f) $\mathrm{CN}_{x-5}$

FIGURE 4: (a) Sharp N-MWCNTs encapsulating a nanowire longer than $500 \mathrm{~nm}$ followed by a cylinder nanoparticle at the tip of the CNT; (b) N-MWCNTs with irregular-shaped metallic nanoparticles; (c) oval-shaped nanoparticle followed by two N-MWCNTs forming a junction; (d) two N-MWCNTs with sharp morphology: one of them has multiple encapsulated metallic nanoparticles; (e) oval lump that shows the graphitic carbon shells formed in the compartments; (f) "oval" nanoparticle encapsulated laterally in the walls of the bamboo structure of N-MWCNTs.

$3500 \mathrm{~cm}^{-1}$. The typical characteristic bands of carbonaceous materials are indicated in the plot, the $\mathrm{D}$ band situated at $1352 \mathrm{~cm}^{-1}$ (defect mode), $\mathrm{G}$ band situated at $1580 \mathrm{~cm}^{-1}$ (graphite mode), and $\mathrm{G}^{\prime}$ located near $2500-2800 \mathrm{~cm}^{-1}$ ( $\mathrm{sec}-$ ond order mode). The peaks appeared in the range 200$500 \mathrm{~nm}$ in two of the spectra $\left(\mathrm{CN}_{x-2}\right.$ and $\mathrm{CN}_{x-3}$, marked with asterisks) which very probably correspond to the presence of iron oxides compounds [36-38], as X-ray diffraction analysis results have shown in such samples. The D band, G band, and $\mathrm{G}^{\prime}$ shifts are within the intervals of $1353 \mathrm{~cm}^{-1}$ to $1359 \mathrm{~cm}^{-1}$, $1587 \mathrm{~cm}^{-1}$ to $1590 \mathrm{~cm}^{-1}$, and $1795 \mathrm{~cm}^{-1}$ to $1712 \mathrm{~cm}^{-1}$, respectively. We can observe a small shifting towards lower frequencies for the samples synthesized using deionized water or aqueous solution with $\mathrm{NaCl}$ with respect to the as-produced with acetone in the residual bubbler, but specifically the $\mathrm{G}$ shifting to lower frequencies indicates a reduction of $\mathrm{N}$ doping for $\mathrm{CN}_{x-2}$ (produced with water). This situation is concomitant with the observation in TGA, where a less reactive sample was observed. We studied the sample from the rates in intensities $I_{\mathrm{D}} / I_{\mathrm{G}}$ and $I_{\mathrm{G}^{\prime}} / I_{\mathrm{G}}$; such values are plotted in Figures 7(b) and 7(c) as a function of the sample. In each sample, the D band intensity is lower than G band intensity. At the same time $G^{\prime}$ band intensity increases as the weight concentration of $\mathrm{NaCl}$ increases. The sample with high degree of disorder or with nongraphitic carbon is the $\mathrm{CN}_{x-2}$ (matches with TGA analysis), followed by $\mathrm{CN}_{x-3}$ whose values are 0.83 and 0.75 , respectively. The most crystalline sample resulted in the $\mathrm{CN}_{x-4}$ with a rate $I_{\mathrm{D}} / I_{\mathrm{G}}$ value of 0.38 . The rate $I_{\mathrm{G}^{\prime}} / I_{\mathrm{G}}$ increases with the increment of density in the liquid, probably indicating that we have quite crystalline samples when substances other than acetone are used in the trap. The $\mathrm{G}^{\prime}$ band is a particular mark of carbonaceous materials; it is higher in pure materials, such as nondoped CNT and graphene.

Figures 8(a)-8(f) exhibit the hysteresis loops measured in the interval $\pm 1 \mathrm{~T}$ for $2 \mathrm{~K}, 100 \mathrm{~K}$, and $300 \mathrm{~K}$ for the $\mathrm{N}$ MWCNTs samples synthesized with different substances in the trap. For each plot, we have included the corresponding SEM images of N-MWCNTs forest grown on $\mathrm{Si} / \mathrm{SiO}_{2}$ (Figures $8(\mathrm{f})-8(\mathrm{j})$ ). In addition, we have drawn the encapsulated nanoparticles observed by TEM to each case. In each 


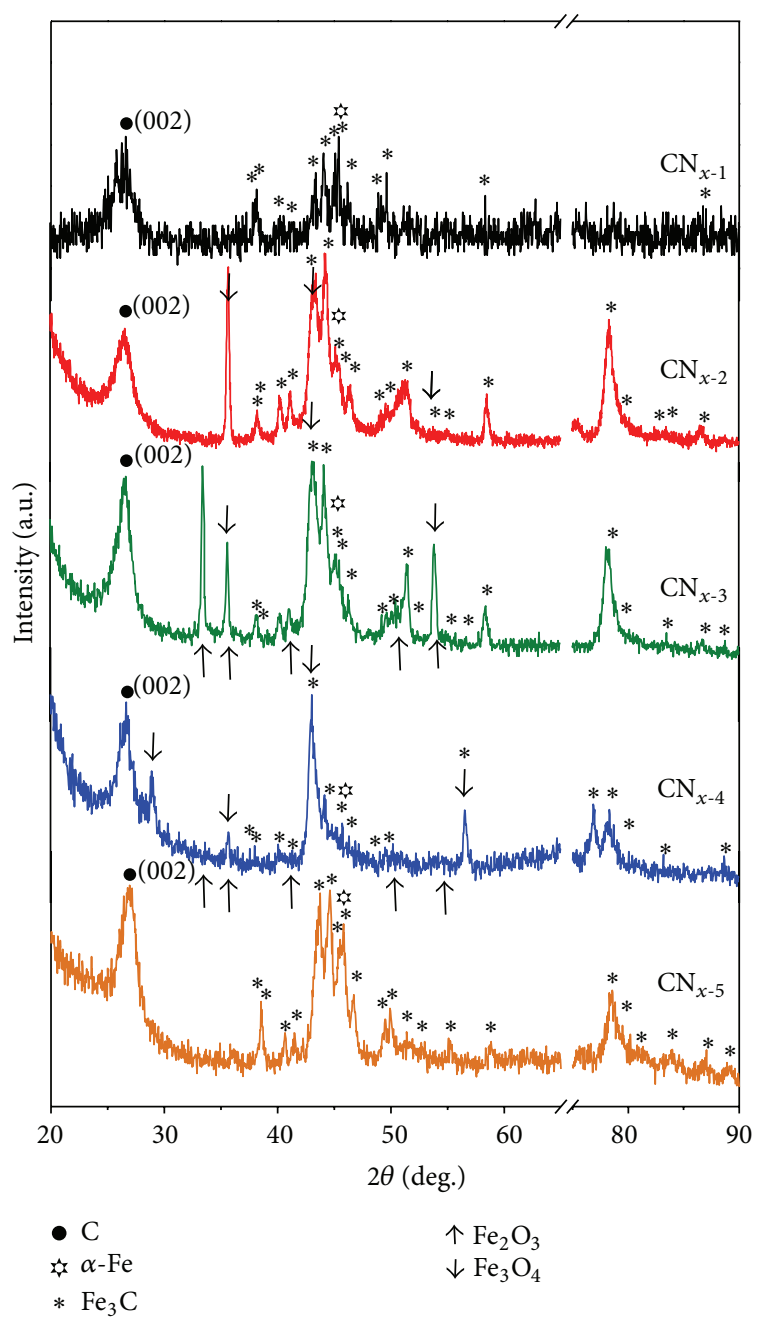

FIgURE 5: X-ray diffractograms for the N-MWCNTs samples synthesized with different liquids in the residual bubbler (trap): $\mathrm{CN}_{x-1}$ (acetone), $\mathrm{CN}_{x-2}$ (water), $\mathrm{CN}_{x-3}$ (low 1 wt. $\%$ of $\mathrm{NaCl}$ ), $\mathrm{CN}_{x-4}$ (halfsaturation, 15.84 wt.\% of $\mathrm{NaCl}$ ), and $\mathrm{CN}_{x-5}$ (saturation, $26.92 \mathrm{wt} . \%$ of $\mathrm{NaCl}$ ).

group of nanoparticles, their intervals of dimensions $(D$ diameter and $L$-length) and aspect ratio (AR) obtained from each sample are listed. In general the magnetic measurements confirm the ferromagnetic nature of the samples. $\mathrm{CN}_{x-1}$ exhibits a hysteresis loop shown in Figure 8(a); the forest is aligned perpendicularly to the substrate, clean and free of amorphous carbon material on its surface. The nanoparticles of this sample have a conical morphology that is usually located at the tip of the N-MWCNTs. As an example, see the SEM image in the blue square for acetone, where you can see the top of the forest of N-MWCNTs. The contrast of the image allows appreciating the conical nanoparticles with maximum aspect ratio of 5 . Their diameters and lengths are within the ranges $20-60 \mathrm{~nm}$ and $90-276 \mathrm{~nm}$, respectively. The inset drawing represents the morphology which can take the nanoparticle when encapsulated by N-MWCNTs. The inserted HRTEM image shows the morphology with conical shape in N-MWCNTs [39]. Hysteresis loops of samples

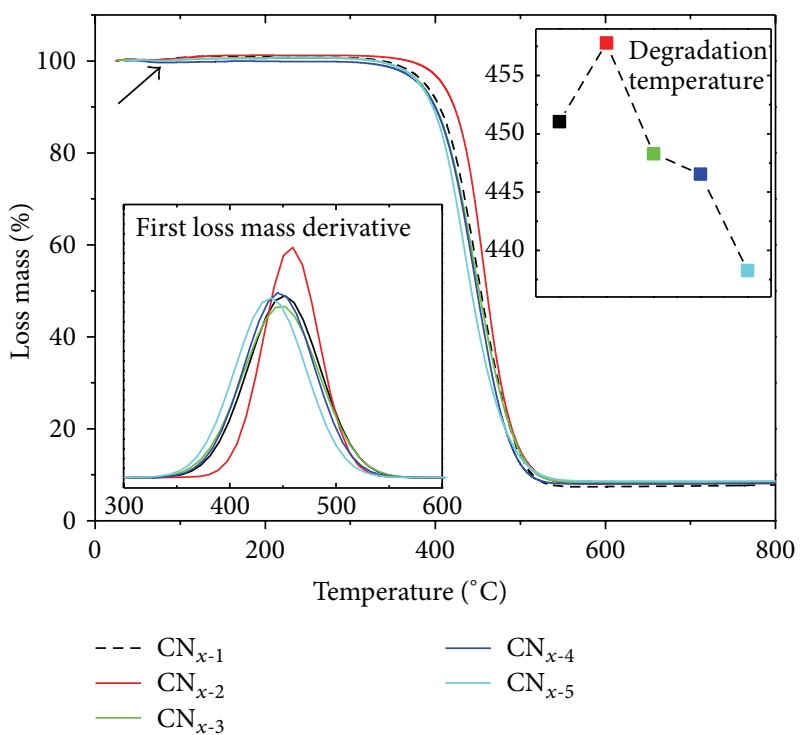

FIGURE 6: Thermogravimetric profile of N-MWCNTs synthesized using different substances in the trap (acetone, deionized water, and three concentrations by weight of $\mathrm{NaCl}$ ). The insets correspond to the first derivative of thermogravimetric profile (left) and degradation temperature.

synthesized with the other substances are similar to acetone (see Figures 8(b)-8(e)), but properties are quite different. The respective forests show that CNTs are also aligned with some defects and amorphous material on the surface (Figures $8(\mathrm{~g})-8(\mathrm{j})$ ). The morphologies of the nanoparticles is totally different from each other (see drawings in each case); we can say that nanoparticles shape is dependent on the type of substance used in the trap. For the cases of $\mathrm{CN}_{x-2}\left(\mathrm{H}_{2} \mathrm{O}\right)$ and $\mathrm{CN}_{x-3}(1 \mathrm{wt} . \% \mathrm{NaCl})$ nanoparticles have very similar morphologies, including nanowires with aspect ratios greater than 5. The diameters and lengths of the nanoparticles for $\mathrm{CN}_{x-2}$ are in the ranges 3-78 $\mathrm{nm}$ and $23-479 \mathrm{~nm}$, respectively, while for $\mathrm{CN}_{x-3}$ the diameters and lengths are within the ranges of $8-60 \mathrm{~nm}$ and $11-348 \mathrm{~nm}$, respectively. The aspect ratios are 16 and 25 for $\mathrm{CN}_{x-2}$ and $\mathrm{CN}_{x-3}$, respectively, and the nanoparticles lengths in $\mathrm{CN}_{x-3}$ can be more than 1 micron. When increasing the $\mathrm{NaCl}$ weight concentration the dimensions of nanoparticles take smaller dimensions. This fact is confirmed by the data reported in each case. $\mathrm{CN}_{x-4}$ (half-saturation of $\mathrm{NaCl}$ ) shows faceted nanoparticle morphologies, with diameter and length within the ranges of $8-60 \mathrm{~nm}$ and $11-348 \mathrm{~nm}$, respectively, and aspect ratio of 10 . $\mathrm{CN}_{x-5}$ (saturated aqueous solution of $\mathrm{NaCl}$ ) has nanoparticles with diameters within the range of 5-22 nm and length of 7$118 \mathrm{~nm}$, with lower aspect ratio of 10 .

The analysis of hysteresis curves (saturation, coercive field, and remanence versus temperature) is presented in Figure 9. The saturation as a function of temperature is exhibited in Figure 9(a) where we can see that it is easier to saturate the ferromagnetic material contained in $\mathrm{CN}_{x-2}$ (water) and $\mathrm{CN}_{x-3}, \mathrm{CN}_{x-4}$, and $\mathrm{CN}_{x-5}$ (with aqueous solutions of $\mathrm{NaCl}$ ) than $\mathrm{CN}_{x-1}$ (acetone). Figure 9(b) presents the plot of coercive field as a function of temperature for the five samples. 


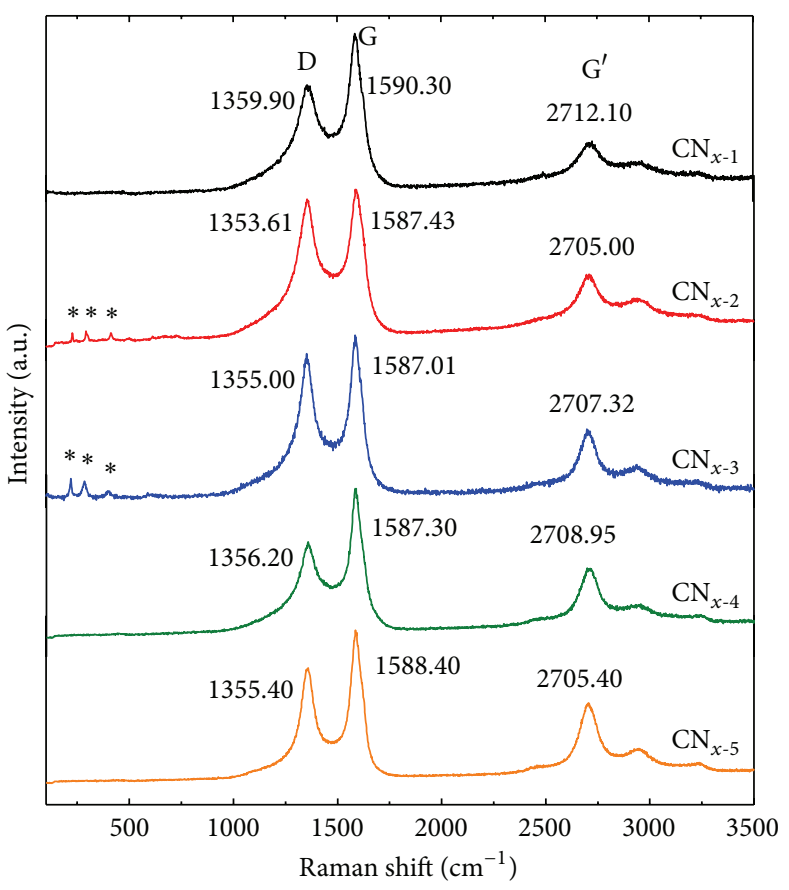

(a)

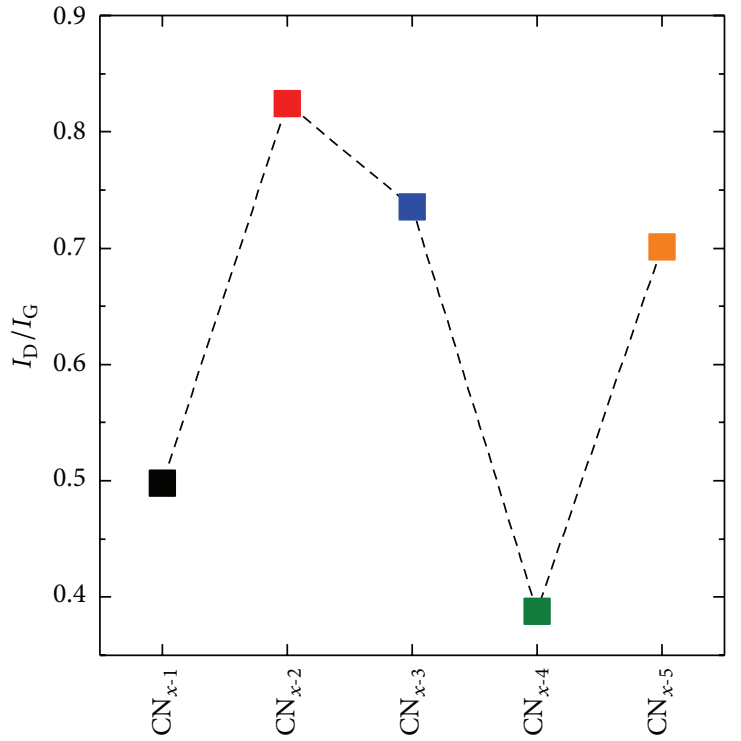

(b)

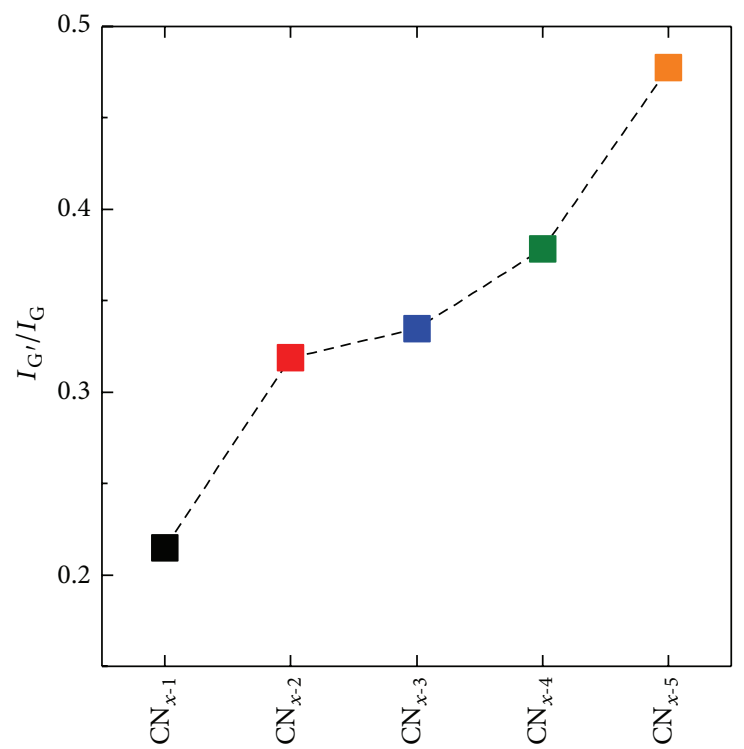

(c)

Figure 7: (a) Raman spectra of N-MWCNTs synthesized using different substances in the residual bubbler: acetone $\left(\mathrm{C}_{3} \mathrm{H}_{6} \mathrm{O}\right)$, water $\left(\mathrm{H}_{2} \mathrm{O}\right)$, and aqueous solution of $\mathrm{NaCl}$ at three weight concentrations (1\%, 15.48\%, and 26.92\%). The RBM: D, G, and $\mathrm{G}^{\prime}$ modes are listed in each spectrum. The asterisks indicate that some peaks related to the signals come from $\mathrm{Si} / \mathrm{SiO}_{2}$ substrates. Rates $(\mathrm{b}) I_{\mathrm{D}} / I_{\mathrm{G}}$ and $(\mathrm{c}) I_{\mathrm{G}^{\prime}} / I_{\mathrm{G}}$ plotted as a function of the sample.

The coercive field decreases when increasing temperature in all samples, but the values decrease for $\mathrm{CN}_{x-2}, \mathrm{CN}_{x-4}$, and $\mathrm{CN}_{x-5}$. The sample $\mathrm{CN}_{x-3}$ is very similar to $\mathrm{CN}_{x-1}$. The remanence, shown in Figure 9(c), has a decreasing trend as a function of temperature for each sample. However, the remanence decreases for the cases of nanoparticles synthesized $\mathrm{N}$-MWCNTs contained in different substances into the trap, with lower values for $\mathrm{CN}_{x-5}$.
According to Figure 9 the most notable changes observed in the magnetic properties are related to the magnetization saturation. Since the iron carbide and $\alpha$-Fe phases are present in all cases, these changes could be associated with the presence of iron oxides phases (see X-ray diffractograms of Figure 5) or due to the morphological changes of magnetic nanoparticles inside or attached to CNT [40, 41]. For example, $\mathrm{CN}_{x-1}$, which is the control sample, presents 


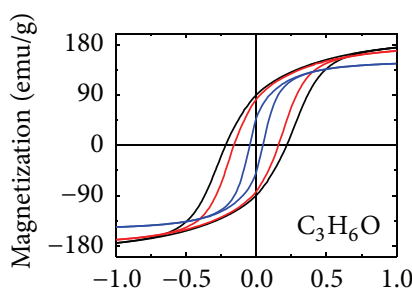

(a)

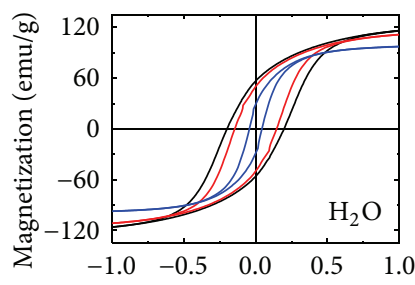

(b)

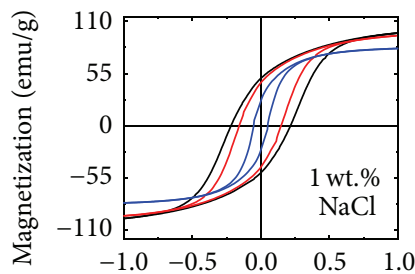

(c)

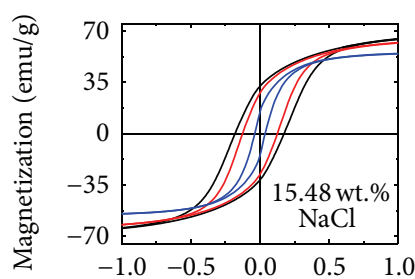

(d)

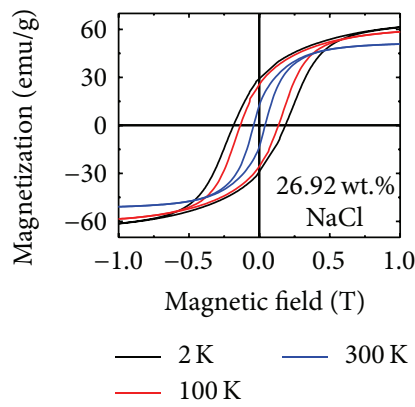

(e)

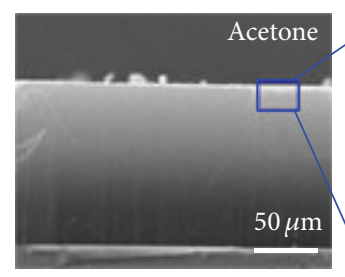

(f)

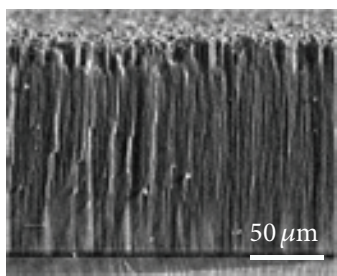

(g)

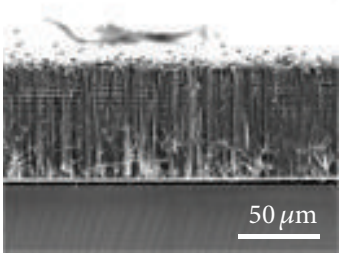

(h)

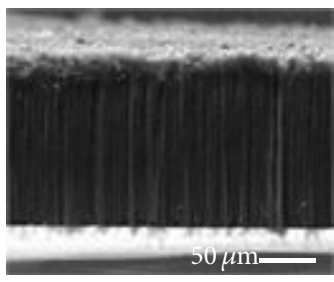

(i)

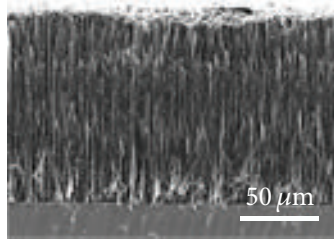

(D) Diameter

(L) Length
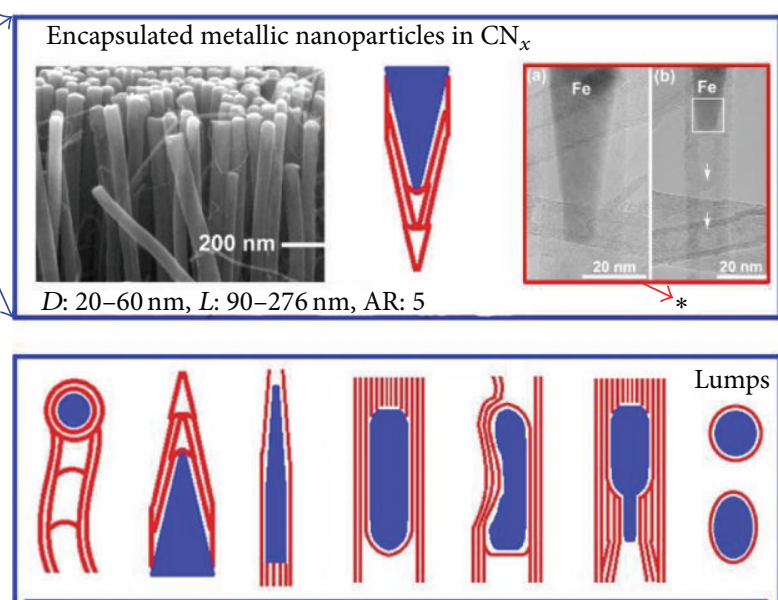

D: $3-78$ nm, L: $13-470$ nm, AR: 16, LD: $1-47$ nm
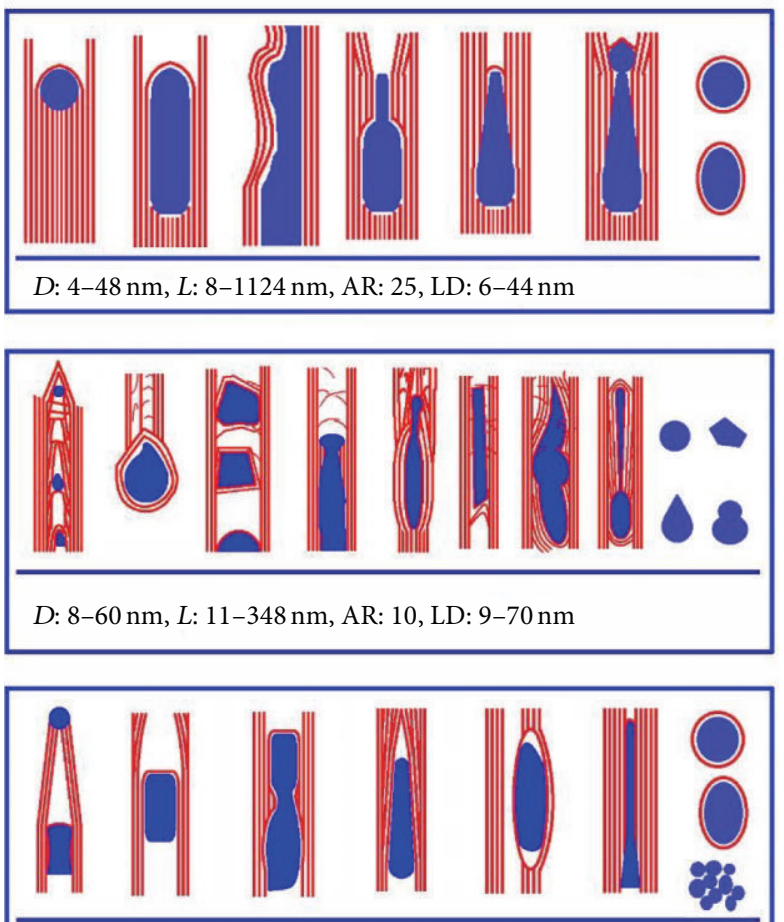

D: 5-22 nm, L: 7-118 nm, AR: 10, LD: 5-48 nm

(AR) Aspect ratio

(y LD) Nanolumps diameter

FIGURE 8: (a-e) Hysteresis loops measured at 2, 200, and $300 \mathrm{~K}$ for encapsulated metallic nanoparticles in $\mathrm{CN}_{x}$ synthesized using different substances inside the trap. (f-j) SEM images of $\mathrm{CN}_{x}$ forests grown over silicon substrates and drawings of the encapsulated nanoparticles in $\mathrm{CN}_{x} \cdot{ }^{*}$ Courtesy and permission from [39].

mostly the typical $\mathrm{Fe}_{3} \mathrm{C}$ with a high saturation magnetization. Although some other important peaks were not observed, it is very probable that $\alpha$-Fe phase is also present (the peak with the maximum intensity is located around 45 degrees). The shape of magnetic nanoparticles in this case is conical with an aspect ratio around 3. Even though the majority of the magnetic phase is also $\mathrm{Fe}_{3} \mathrm{C}$ in $\mathrm{CN}_{x-2}$ samples, the saturation magnetization is reduced when water is used in the trap (see Figure 8(b)). One of the probable explanations to this behavior is the morphology changes in the nanoparticles. A statistical analysis was performed to 60 TEM images of $\mathrm{CN}_{x-2}$ case, which showed that $34 \%$ of the nanoparticles 


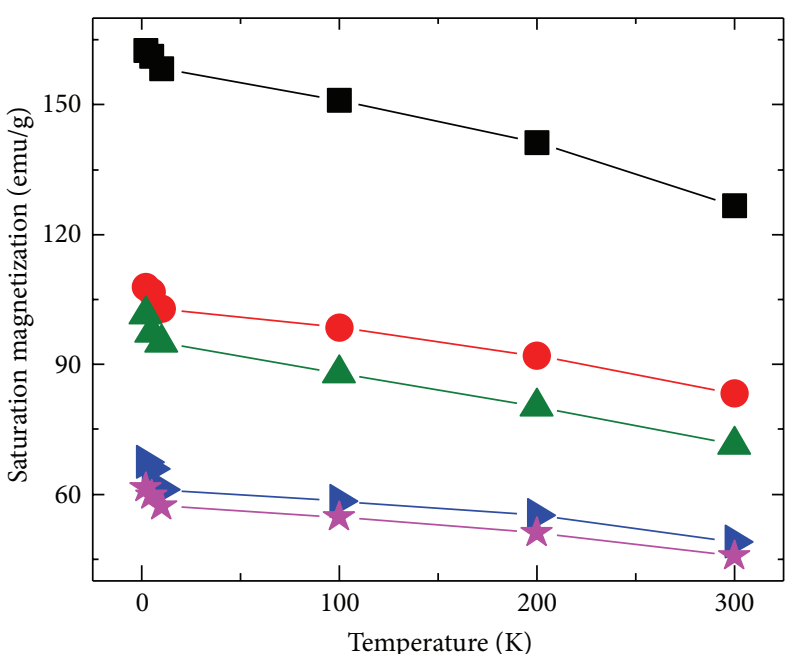

(a)

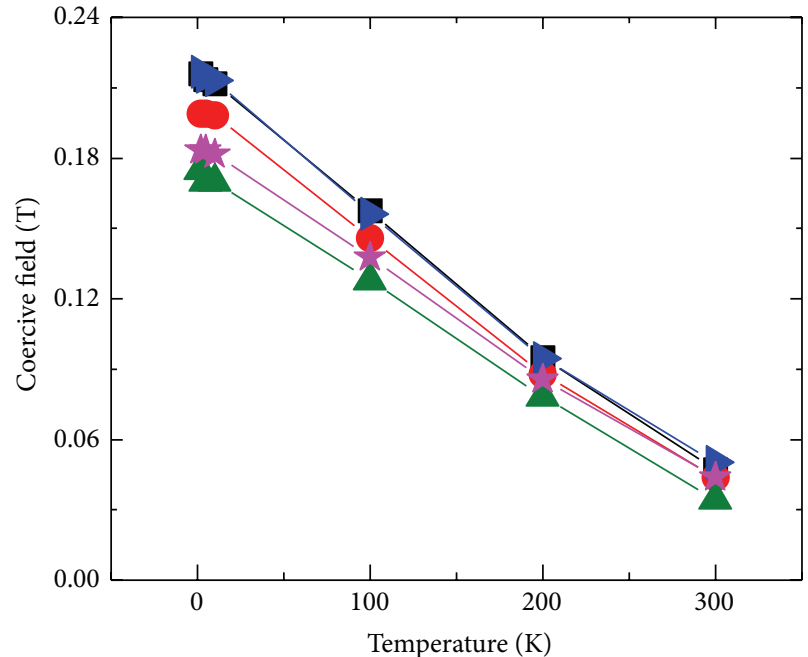

(b)

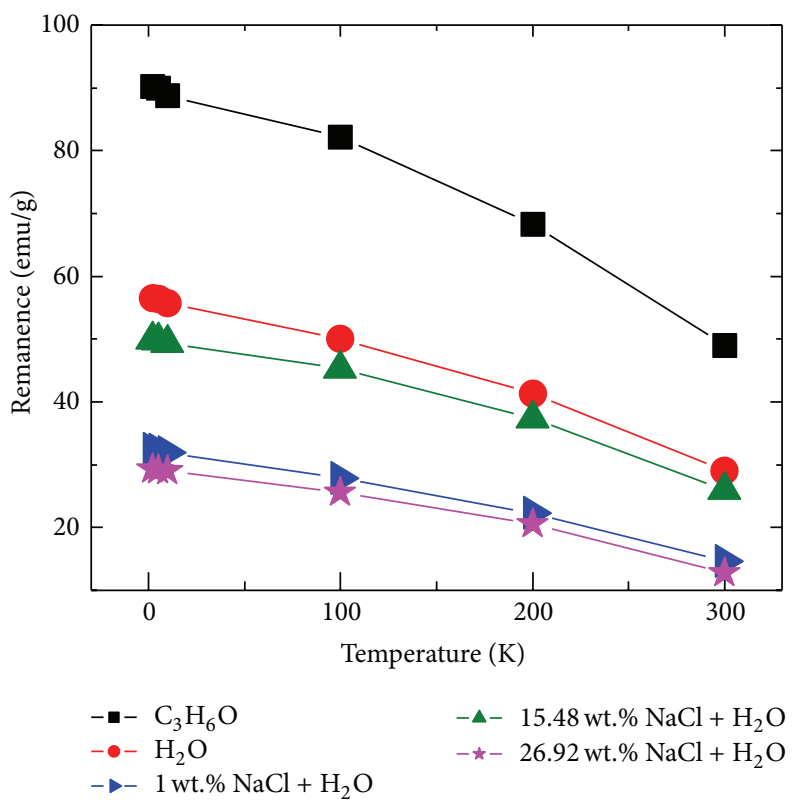

(c)

FIGURE 9: (a) Saturation, (b) coercivity, and (c) remanence values as a function of temperature for encapsulated metallic nanoparticles in $\mathrm{CN}_{x}$ synthesized in acetone $\left(\mathrm{CN}_{x-1}\right)$, water $\left(\mathrm{CN}_{x-2}\right)$, and various concentrations by weight $\mathrm{NaCl}$ in water $\left(\mathrm{CN}_{x-3}, \mathrm{CN}_{x-4}\right.$, and $\left.\mathrm{CN}_{x-5}\right)$.

have a spherical shape (first drawing) and the other $66 \%$ presented other kinds of morphologies (see right drawings of Figure $8(\mathrm{~g})$ ). The reduction of the saturation magnetization in this case is around $33.3 \%$, which is approximately the percentage of nanoparticles which are spherical in type. However, there is another source that could contribute to the reduction of saturation magnetization, namely, the magnetite phase present in this sample. The peak at around 35 degrees shows the existence of that phase in sample $\mathrm{CN}_{x-2}$ (see $\mathrm{CN}_{x-2}$ diffractogram in Figure 5). Note that it was not possible to observe the peak having the second strongest value, which is around 62 degrees. Magnetite in bulk phase has a saturation magnetization of around $85-100 \mathrm{emu} / \mathrm{g}$, which is around $50 \%$ lower than the respective saturation magnetizations of $\mathrm{Fe}_{3} \mathrm{C}$ (169 emu/g for bulk) phase [42-45]. Therefore, a combination of such effects could be the cause of the observed changes. In the case of $\mathrm{CN}_{x-3}$ the statistical analysis yielded the fact that only $6.8 \%$ of the magnetic nanoparticles have a spherical shape. Therefore, the effect of morphology changes of magnetic nanoparticles may not be important. However, now the $\gamma-\mathrm{Fe}_{2} \mathrm{O}_{3}$ phase is present in this sample and could be one of the cause of the reduction of saturation magnetization. If the $\mathrm{CN}_{x-2}$ and $\mathrm{CN}_{x-3} \mathrm{X}$-ray diffractograms of Figure 5 are compared, it is possible to observe that in the $\mathrm{CN}_{x-3}$ case two additional diffraction peaks are present. These peaks are around 34 and 54 degrees and might be associated with (311) and (422) planes of the maghemite $\left(\gamma-\mathrm{Fe}_{2} \mathrm{O}_{3}\right)$ phase, which has around $90 \mathrm{emu} / \mathrm{g}$ of saturation magnetization in the case 
of bulk phase. The presence of $\gamma-\mathrm{Fe}_{2} \mathrm{O}_{3}$ and $\mathrm{Fe}_{3} \mathrm{O}_{4}$ phases could be causing the saturation magnetization to reduce by more than 50\% (see Figure 9(a)). An interesting situation is observed in the X-ray diffractogram of case $\mathrm{CN}_{x-4}$. The diffraction peaks corresponding to (311) and (422) planes of the maghemite phase are not present anymore and the structure corresponding to the $\mathrm{Fe}_{3} \mathrm{C}$ phase is drastically modified (see Figure $5 \mathrm{CN}_{x-4}$ case). Also, the diffraction peak at 35 degrees related to the $\mathrm{Fe}_{3} \mathrm{O}_{4}$ magnetite phase is notably reduced. In addition, three new diffraction peaks are present, namely, at around 29, 56, and 77 degrees. The first two peaks correspond to (220) and (551) planes of magnetite and the last peak corresponds to (140) plane of cementite. Note how the intensity of the peak at around 43 degrees is greatly increased in comparison with the other $\mathrm{Fe}_{3} \mathrm{C}$ diffraction peaks. This peak can also be associated with the (400) plane of magnetite. Apparently, the magnetic behavior in this case is due to different causes than the previous situations. It is probable that the magnetic magnetite, cementite, and $\alpha$-Fe phases are those that determine the behavior of the saturation magnetization. Note also that the phase of maghemite was not well observed. Figure S8 (Supplementary Information) shows that, in elongated nanoparticles, mostly $\alpha$-Fe and cementite phases are contained. In this case, in order to explain the increase of saturation of magnetization, additional information that we need to consider is the morphological changes experienced by magnetic nanoparticles. The drawings on the left side of Figure 8(i) show complex structures of the encapsulated nanoparticles in $\mathrm{CN}_{x-4}$. According to a statistical analysis, it was found that only $8.6 \%$ of them have spherical shape and the rest present an elongated structure. It is noteworthy that some nanoparticles have square-type morphology (see Figure S7 in Supplementary Information). Finally, the X-ray diffractogram of $\mathrm{CN}_{x-5}$ does not show any Fe-oxides phases. Only defined diffraction peaks of $\mathrm{Fe}_{3} \mathrm{C}$ and $\alpha$-Fe planes were observed. It seems that, in this case, the morphology changes are the only ones responsible for the observed decrease of saturation magnetization (more than 50\%). Figure S9 shows several HRTEM images of such nanoparticles. These particles take different shapes such as spherical (13\%), cylindrical $(28 \%)$, deformed $(23 \%)$, seed $(28 \%)$, oval $(5 \%)$, and arrow (3\%) [27]. It is well known that if the morphologies of the ferromagnetic nanoparticles are different, it is very probable that the process of magnetization will be strongly dependent upon their shape and size and also on the applied magnetic field direction $[39,41]$. The irregular shapes of ferromagnetic nanoparticles in this $\mathrm{CN}_{x-5}$ case could have reduced the saturation magnetization due to surface or finite size effects $[46,47]$. Note that the coercivity values follow the trend in aspect ratio where $\mathrm{CN}_{x-3}$ with an aspect ratio of 25 had the highest values and the samples with the lowest aspect ratio of $10\left(\mathrm{CN}_{x-4}\right.$ and $\left.\mathrm{CN}_{x-5}\right)$ exhibited the lowest coercivity (see drawings of Figure 8).

The resistance of the N-MWCNTs was measured by the four-probe method as a function of the temperature in the range $2-395 \mathrm{~K}$ (Figure 10). The resistance of $\mathrm{CN}_{x-2}$ is an order of magnitude higher than $\mathrm{CN}_{x-1}$ and $\mathrm{CN}_{x-3}$ (Figure 10(a)), but the three resistance curves have similar behavior. However the resistance of $\mathrm{CN}_{x-4}$ and $\mathrm{CN}_{x-5}$ (Figure 10(b)) is two orders of magnitude lower than $\mathrm{CN}_{x-1}$ with a different curve behavior. All samples showed two kinds of behaviors of electronic transport. The samples $\mathrm{CN}_{x-1}, \mathrm{CN}_{x-2}$, and $\mathrm{CN}_{x-3}$ showed semiconducting electronic transport with very large values of resistivity at low temperatures $(2 \mathrm{~K})$. The samples $\mathrm{CN}_{x-4}$ and $\mathrm{CN}_{x-5}$ : (i) at very low temperatures (below $20 \mathrm{~K}$ ) the slope of the resistance increases when temperature decreases; (ii) between $20 \mathrm{~K}$ and $300 \mathrm{~K}$, the resistance increases with the increment of temperature showing metallic behavior. It is not possible to associate these two last behaviors with the N-MWCNTs themselves. However, it is very probable that some $\mathrm{Na}$ contamination of the substrates during the synthesis occurred. Results from OES characterization of samples (substrates and N-MWCNTs) obtained by the additional experiments, which were performed to verify the effect of trap substance over morphology and physical properties, showed that when the trap is filled with aqueous solution of $\mathrm{NaCl}$ (15.84 wt.\% case) a gram of N-MWCNTs contains $0.204 \mathrm{mg}$ of $\mathrm{Na}$ and in each gram of $\mathrm{Si}$ substrate there is $0.00835 \mathrm{mg}$ of $\mathrm{Na}$. This could explain the metallic transport at temperatures above $20 \mathrm{~K}$. Similar kind of effect has been observed by pdoping with the intercalation of $\mathrm{I}, \mathrm{K}$, and $\mathrm{Br}$ within SWNT bundles, with a metallic-like behavior at high temperatures $(>50 \mathrm{~K})$ and semiconducting behavior at lower temperatures $(<50 \mathrm{~K})[48,49]$. However the mechanism is not yet well understood and we encourage more research regarding this effect.

In the CVD experiment we are proposing the use of different liquids other than acetone. We have used water and aqueous solutions of $\mathrm{NaCl}$ at three weight concentrations $(1 \%$; $15.48 \%$, half-saturation; and $26.92 \%$, saturation). In all cases we consider that a reflux evaporation of water molecules and some atoms of $\mathrm{Na}$ or $\mathrm{Cl}$ are entering to the hot zone of the furnace and participating in the catalysis of N-MWCNTs. The feedstock that contains the $\mathrm{C}, \mathrm{Fe}$, and $\mathrm{N}$ is carried by the argon gas. However, it seems that the reflux evaporation is also present in the process of synthesis. For example, in the case of water the oxygen directly affects the catalytic particles, keeping the catalyst alive $[13,14]$. This effect could be responsible for the different nanoparticle shapes that catalyze N-MWCNTs in different morphologies, sizes, and diameters. In the case of $\mathrm{H}$, this can be associated with C forming hydrocarbons which probably could be cleaned by the gas. In the case of the presence of $\mathrm{NaCl}$ the steps are similar, but the water evaporation is different because $\mathrm{NaCl}$ was solubilized in water, where the water molecules are attracted by the $\mathrm{Na}^{+}$and $\mathrm{Cl}^{-}$ions. The water is attracted by the crystal structure in the individual ions encircling and dissolving slowly the $\mathrm{NaCl}$. The water molecules alignment depends on the ion kind $\left(\mathrm{Na}^{+}\right.$or $\left.\mathrm{Cl}^{-}\right)$. The negative part of water molecule $(\mathrm{O})$ surrounds the $\mathrm{Na}^{+}$ion, while the positive side (H) surrounds the $\mathrm{Cl}^{-}$ion. Taking into account this limitation to water, we may consider the fact that less water vapor is refluxing to the hot zone as well as some $\mathrm{Na}^{+}$ or $\mathrm{Cl}^{-}$are entering by the water evaporation. In the case of saturated $\mathrm{NaCl}$ there are not available water molecules due to the fact all of them are associated with ions. First, water molecules and ions surrounded by water molecules are contaminating the feedstock deposited in the substrate. CNT 


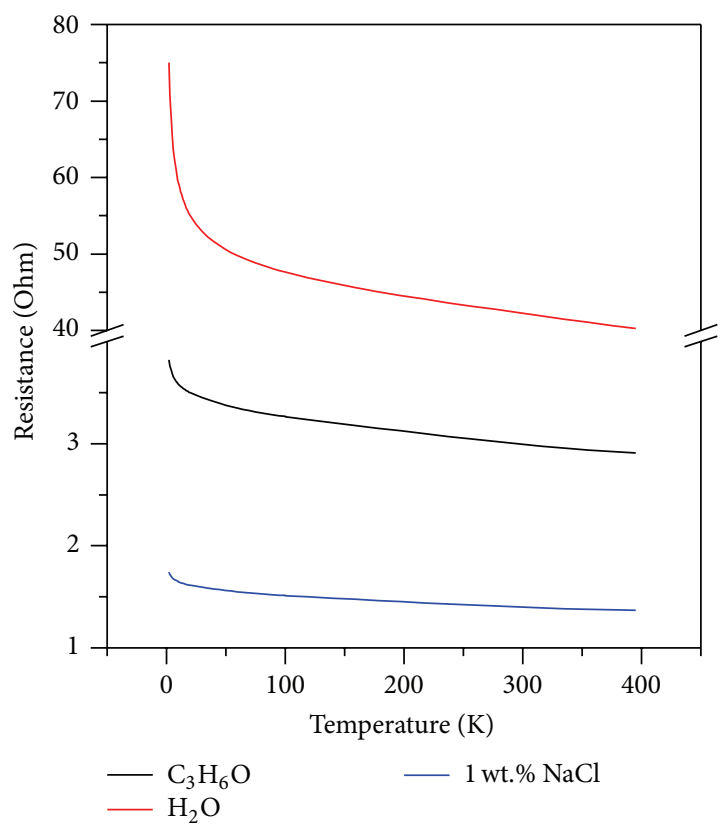

(a)

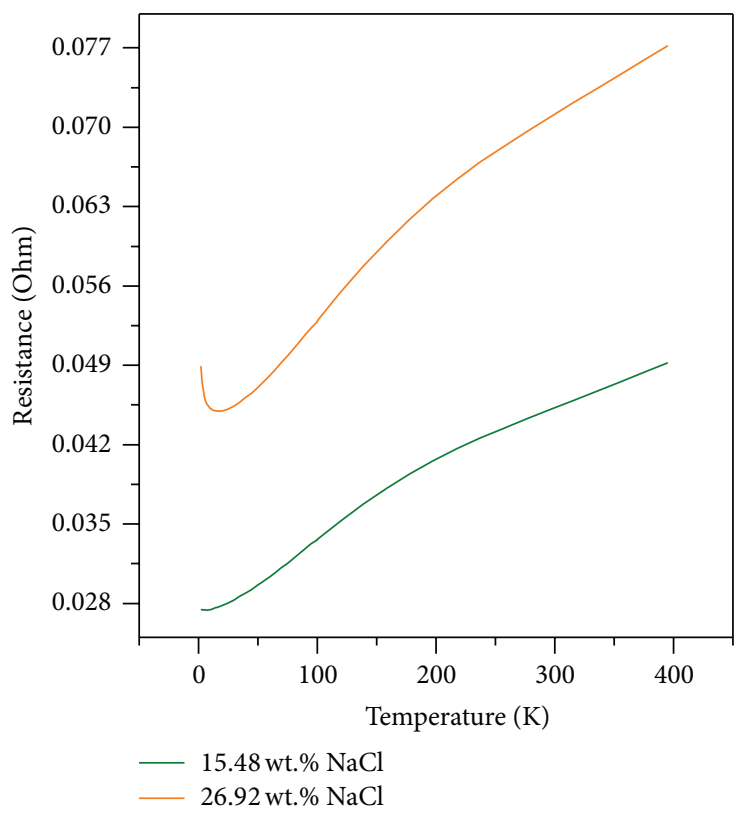

(b)

FIGURE 10: Resistance behavior of $\mathrm{CN}_{x}$ synthesized with different substances in the residual bubbler of CVD setup. (a) Black line corresponds to $\mathrm{CN}_{x-1}$ (acetone), red line to $\mathrm{CN}_{x-2}$ (water), and blue line to $\mathrm{CN}_{x-3}$ (aqueous solution of $1 \mathrm{wt} \%$ of $\mathrm{NaCl}$ ) and (b) red line corresponds to $\mathrm{CN}_{x-4}$ (aqueous solution of $15.48 \mathrm{wt} . \%$ of $\mathrm{NaCl}$ ) and orange line to $\mathrm{CN}_{x-5}$ (aqueous solution of $26.92 \mathrm{wt} . \%$ of $\mathrm{NaCl}$ ). $\mathrm{Resistances}$ of $\mathrm{CN}_{x-1}$, $\mathrm{CN}_{x-2}$, and $\mathrm{CN}_{x-3}$ have typical semiconducting behavior. At the same time, the samples prepared with aqueous solution $\mathrm{NaCl}$ in the residual bubbler show metallic response above $20 \mathrm{~K}$ and semiconducting behavior at very low temperature.

has started growing but encapsulating small nanoparticles, at different sites in the hollow structure. The effects of the water molecules have an effect similar to the previous case, but in this case the $\mathrm{Na}$ or $\mathrm{Cl}$ ions are also participating in the catalysis, probably reducing the sizes of nanoparticles. In order to alternatively test how the $\mathrm{Na}$ or $\mathrm{Cl}$ could be affecting the growing of carbon nanotubes a specific experiment was performed. Instead of introducing aqueous solution of $\mathrm{NaCl}$ (case $15.84 \mathrm{wt} . \%$ ) inside the trap, a more complicated CVD setup was used to fabricate the carbon nanotubes (see Figure S5 in Supplementary Information). In this case two sprayers were used, one with the typical solution containing benzylamine and ferrocene and the other with an aqueous solution of $\mathrm{NaCl}$. Both systems were switched on at same time with different sprayer conditions of frequency and power to tray to obtain similar results to the original experiment with the trap. A total of $335 \mathrm{mg}$ of powder was obtained from the quartz tube. Figure S6 (Supplementary Information) shows the fabricated N-MWCNTs selected from different part of the sample, which show different lengths but similar aspect at the magnification showed (see Supplementary Information) [50]. From these images it was possible to observe the dramatic damages due to the $\mathrm{NaCl}$ vapor introduced in the synthesis. More research using this bi-sprayer system is in progress.

\section{Summary}

The CVD configuration was modified to synthesize controlled morphologies in nitrogen-doped carbon nanotubes by increasing the density of the liquid trap used in the bubbler. The SEM and HRTEM images revealed the fact that the morphology of N-MWCNTs was modified substantially exploding the versatility of CVD. We studied the present morphologies in the sample by observing the hollow core morphology, which resulted in the fact that the bamboo structure not only was observed, but also collapsed, MWCNT, and different junctions. When increasing the density of the liquid in the residual bubbler it affected not only the tube morphology, but also the metallic nanoparticles morphology. $\mathrm{X}$-Ray diffraction showed the presence of different phases of iron such as oxides (magnetite and maghemite) and most of the planes were observed in N-MWCNTs synthesized with water $\left(\mathrm{CN}_{x-2}\right)$ and low concentration of $\mathrm{NaCl}+\mathrm{H}_{2} \mathrm{O}$ $\left(\mathrm{CN}_{x-3}\right)$ in the bubbler. The peaks of planes of iron oxides are not usually observed in samples of N-MWCNTs synthesized with acetone in the bubbler. Raman and thermogravimetric analysis exhibited the fact that water produces a noncrystalline sample that could be attributed to the high degree of disorder in the sample or high level of amorphous carbon. Yet, the presence of $\mathrm{NaCl}$ in water showed samples with higher crystalline structure and more reactivity. Magnetic measurements lower coercive fields, remanence, and saturation for the increment of $\mathrm{NaCl}$. Resistivity plots revealed the semiconducting nature of the N-MWCNTs synthesized with water and low $\mathrm{NaCl}$, similar to acetone, but with different orders of magnitude. The samples synthesized with aqueous solution of $\mathrm{NaCl}$ showed metallic behavior due to the fact that the resistances were increased with the increment of temperature. 
More sophisticated experiments can be designed to tune the morphological and chemical and physical properties of $\mathrm{N}$ MWCNTs.

\section{Conflict of Interests}

The authors declare that there is no conflict of interests regarding the publication of this paper.

\section{Acknowledgments}

Authors thank the support by CONACYT-Mexico grants: Fondo Mixto de San Luis Potosí 63001 S-3908 and 63072 S-3909 (Emilio Muñoz-Sandoval), 48300 (Emilio MuñozSandoval), and CONACyT Scholarship of María Luisa García-Betancourt no. 223824. María Luisa García-Betancourt also thanks access to LINAN-IPICyT and Physics Department, Penn State, for experimentation and characterization in development of $\mathrm{PhD}$ thesis project. They thank B. RiveraEscoto, G. Labrada, F. Tristan, H. Martínez, and D. Ramírez for technical support.

\section{References}

[1] A. Oberlin, M. Endo, and T. Koyama, "Filamentous growth of carbon through benzene decomposition," Journal of Crystal Growth, vol. 32, no. 3, pp. 335-349, 1976.

[2] S. Iijima, "Helical microtubules of graphitic carbon," Nature, vol. 354, no. 6348, pp. 56-58, 1991.

[3] L. Ding, A. Tselev, J. Wang et al., "Selective growth of wellaligned semiconducting single-walled carbon nanotubes," Nano Letters, vol. 9, no. 2, pp. 800-805, 2009.

[4] N. Yamamoto, A. J. Hart, E. J. Garcia et al., "High-yield growth and morphology control of aligned carbon nanotubes on ceramic fibers for multifunctional enhancement of structural composites," Carbon, vol. 47, no. 3, pp. 551-560, 2009.

[5] B. H. Hong, J. P. Small, M. S. Purewal et al., "Extracting subnanometer single shells from ultralong multiwalled carbon nanotubes," Proceedings of the National Academy of Sciences of the United States of America, vol. 102, no. 40, pp. 14155-14158, 2005.

[6] K. T. Constantopoulos, C. J. Shearer, A. V. Ellis, N. H. Voelcker, and J. G. Shapter, "Carbon nanotubes anchored to silicon for device fabrication," Advanced Materials, vol. 22, no. 5, pp. 557571, 2010.

[7] M. A. Mohamed, N. Inami, E. Shikoh, Y. Yamamoto, H. Hori, and A. Fujiwara, "Fabrication of spintronics device by direct synthesis of single-walled carbon nanotubes from ferromagnetic electrodes," Science and Technology of Advanced Materials, vol. 9, no. 2, Article ID 025019, 2008.

[8] P. M. Ajayan and O. Z. Zhou, "Applications of carbon nanotubes," in Carbon Nanotubes, pp. 391-425, Springer, Berlin, Germany, 2001.

[9] S.-H. Jeong, O.-J. Lee, K.-H. Lee, S.-H. Oh, and C.-G. Park, "Packing density control of aligned carbon nanotubes," Chemistry of Materials, vol. 14, no. 10, pp. 4003-4005, 2002.

[10] J. Zhao, H. Park, J. Han, and J. P. Lu, "Electronic properties of carbon nanotubes with covalent sidewall functionalization," The Journal of Physical Chemistry B, vol. 108, no. 14, pp. 4227-4230, 2004.
[11] S. Bellucci, "Carbon nanotubes: physics and applications," physica status solidi C, vol. 2, no. 1, pp. 34-47, 2005.

[12] J.-C. Charlier, "Defects in carbon nanotubes," Accounts of Chemical Research, vol. 35, no. 12, pp. 1063-1069, 2002.

[13] K. Hata, D. N. Futaba, K. Mizuno, T. Namai, M. Yumura, and S. Iijima, "Water-assisted highly efficient synthesis of impurityfree single-walled carbon nanotubes," Science, vol. 306, no. 5700, pp. 1362-1364, 2004.

[14] T. Yamada, A. Maigne, M. Yudasaka et al., "Revealing the secret of water-assisted carbon nanotube synthesis by microscopic observation of the interaction of water on the catalysts," Nano Letters, vol. 8, no. 12, pp. 4288-4292, 2008.

[15] L. Ding, A. Tselev, J. Wang et al., "Selective growth of wellaligned semiconducting single-walled carbon nanotubes," Nano Letters, vol. 9, no. 2, pp. 800-805, 2009.

[16] Y. Zhang and X. Sun, "Synthesis of carbon nanofibers and foam by catalytic chemical vapor deposition using a water-soluble alkali salt catalyst," Advanced Materials, vol. 19, no. 7, pp. 961964, 2007.

[17] Y. Qin, Y. Zhang, and X. Sun, "Synthesis of helical and straight carbon nanofibers by chemical vapor deposition using alkali chloride catalysts," Microchimica Acta, vol. 164, no. 3-4, pp. 425430, 2009.

[18] R. Lv, F. Kang, W. Wang et al., "Effect of using chlorinecontaining precursors in the synthesis of FeNi-filled carbon nanotubes," Carbon, vol. 45, no. 7, pp. 1433-1438, 2007.

[19] X. Gui, K. Wang, W. Wang et al., "The decisive roles of chlorinecontained precursor and hydrogen for the filling Fe nanowires into carbon nanotubes," Materials Chemistry and Physics, vol. 113, no. 2-3, pp. 634-637, 2009.

[20] D. Wei and Y. Liu, "The intramolecular junctions of carbon nanotubes," Advanced Materials, vol. 20, no. 15, pp. 2815-2841, 2008.

[21] C. Zhou, J. Kong, E. Yenilmez, and H. Dai, "Modulated chemical doping of individual carbon nanotubes," Science, vol. 290, no. 5496, pp. 1552-1555, 2000.

[22] J. M. Romo-Herrera, D. A. Cullen, E. Cruz-Silva et al., "The role of sulfur in the synthesis of novel carbon morphologies: From covalent Y-junctions to sea-urchin-like structures," Advanced Functional Materials, vol. 19, no. 8, pp. 1193-1199, 2009.

[23] X. Lepró, Y. Vega-Canú, F. J. Rodríguez-Macías, Y. Bando, D. Golberg, and M. Terrones, "Production and characterization of coaxial nanotube junctions and networks of $\mathrm{CN}_{x} / \mathrm{CNT}$, Nano Letters, vol. 7, no. 8, pp. 2220-2226, 2007.

[24] Z. Jin, X. Li, W. Zhou, Z. Han, Y. Zhang, and Y. Li, "Direct growth of carbon nanotube junctions by a two-step chemical vapor deposition," Chemical Physics Letters, vol. 432, no. 1-3, pp. 177-183, 2006.

[25] Q. Liu, W. Liu, Z.-M. Cui, W.-G. Song, and L.-J. Wan, "Synthesis and characterization of 3D double branched $\mathrm{K}$ junction carbon nanotubes and nanorods," Carbon, vol. 45, no. 2, pp. 268-273, 2007.

[26] D. Wei, Y. Liu, L. Cao et al., "A new method to synthesize complicated multibranched carbon nanotubes with controlled architecture and composition," Nano Letters, vol. 6, no. 2, pp. 186-192, 2006

[27] M. L. García-Betancourt, Y. Vega-Cantu, S. M. Vega-Díaz et al., "Synthesis, characterization and magnetic properties of defective nitrogen-doped multiwall carbon nanotubes encapsulating ferromagnetic nanoparticles," Journal of Nano Research, vol. 28, pp. 39-49, 2014. 
[28] M. L. García-Betancourt, N. Perea Lopez, S. M. Vega-Díaz et al., "Pinetree-like morphologies of nitrogen-doped carbon nanotubes: electron field emission enhancement," Journal of Materials Research, vol. 29, pp. 2441-2450, 2014.

[29] J. W. Jang, C. E. Lee, S. C. Lyu, T. J. Lee, and C. J. Lee, "Structural study of nitrogen-doping effects in bamboo-shaped multiwalled carbon nanotubes," Applied Physics Letters, vol. 84, no. 15, pp. 2877-2879, 2004.

[30] E. N. Nxumalo and N. J. Coville, "Nitrogen doped carbon nanotubes from organometallic compounds: a review," Materials, vol. 3, no. 3, pp. 2141-2171, 2010.

[31] J. Y. Lao, W. Z. Li, J. G. Wen, and Z. F. Ren, "Boron carbide nanolumps on carbon nanotubes," Applied Physics Letters, vol. 80, no. 3, pp. 500-502, 2002.

[32] C.-M. Seah, S.-P. Chai, and A. R. Mohamed, "Synthesis of aligned carbon nanotubes," Carbon, vol. 49, no. 14, pp. 46134635, 2011.

[33] X. Li, X. Zhang, L. Ci et al., "Air-assisted growth of ultralong carbon nanotube bundles," Nanotechnology, vol. 19, no. 45, Article ID 455609, 2008.

[34] V. O. Khavrus, E. M. M. Ibrahim, A. Leonhardt et al., "Conditions of simultaneous growth and separation of single- and multiwalled carbon nanotubes," Journal of Physical Chemistry C, vol. 114, no. 2, pp. 843-848, 2010.

[35] T. Sharifi, F. Nitze, H. R. Barzegar et al., "Nitrogen doped multi walled carbon nanotubes produced by CVD-correlating XPS and Raman spectroscopy for the study of nitrogen inclusion," Carbon, vol. 50, no. 10, pp. 3535-3541, 2012.

[36] D. Bersani, P. P. Lottici, and A. Montenero, "Micro-Raman investigation of iron oxide films and powders produced by solgel syntheses," Journal of Raman Spectroscopy, vol. 30, no. 5, pp. 355-360, 1999.

[37] C. J. Sartoretti, B. D. Alexander, R. Solarska, I. A. Rutkowska, J. Augustynski, and R. Cerny, "Photoelectrochemical oxidation of water at transparent ferric oxide film electrodes," Journal of Physical Chemistry B, vol. 109, no. 28, pp. 13685-13692, 2005.

[38] Y.-S. Li, J. S. Church, A. L. Woodhead, and F. Moussa, "Preparation and characterization of silica coated iron oxide magnetic nano-particles," Spectrochimica Acta Part A: Molecular and Biomolecular Spectroscopy, vol. 76, no. 5, pp. 484-489, 2010.

[39] F. López-Urías, E. Muñoz-Sandoval, M. Reyes-Reyes, A. H. Romero, M. Terrones, and J. L. Morán-López, "Creation of helical vortices during magnetization of aligned carbon nanotubes filled with Fe: Theory and experiment," Physical Review Letters, vol. 94, no. 21, Article ID 216102, 2005.

[40] C. Cannas, D. Gatteschi, A. Musinu, G. Piccaluga, and C. Sangregorio, "Structural and magnetic properties of $\mathrm{Fe}_{2} \mathrm{O}_{3}$ nanoparticles dispersed over a silica matrix," The Journal of Physical Chemistry B, vol. 102, no. 40, pp. 7721-7726, 1998.

[41] A. Morelos-Gómez, F. López-Urías, E. Muñoz-Sandoval et al., "Controlling high coercivities of ferromagnetic nanowires encapsulated in carbon nanotubes," Journal of Materials Chemistry, vol. 20, no. 28, pp. 5906-5914, 2010.

[42] A. Demir, A. Baykal, H. Sözeri, and R. Topkaya, "Low temperature magnetic investigation of $\mathrm{Fe}_{3} \mathrm{O}_{4}$ nanoparticles filled into multiwalled carbon nanotubes," Synthetic Metals, vol. 187, no. 1, pp. 75-80, 2014.

[43] X. Wang, Z. Zhao, J. Qu, Z. Wang, and J. Qiu, "Fabrication and characterization of magnetic $\mathrm{Fe}_{3} \mathrm{O}_{4}$-CNT composites," Journal of Physics and Chemistry of Solids, vol. 71, no. 4, pp. 673-676, 2010.
[44] F. S. Boi, G. Mountjoy, R. M. Wilson, Z. Luklinska, L. J. Sawiak, and M. Baxendale, "Multiwall carbon nanotubes continuously filled with micrometre-length ferromagnetic alpha-Fe nanowires," Carbon, vol. 64, pp. 351-358, 2013.

[45] D. L. Peng, X. Zhao, S. Inoue, Y. Ando, and K. Sumiyama, "Magnetic properties of Fe clusters adhering to single-wall carbon nanotubes," Journal of Magnetism and Magnetic Materials, vol. 292, pp. 143-149, 2005.

[46] H. M. Lu, W. T. Zheng, and Q. Jiang, "Saturation magnetization of ferromagnetic and ferrimagnetic nanocrystals at room temperature," Journal of Physics D: Applied Physics, vol. 40, no. 2, pp. 320-325, 2007.

[47] N. Grobert, W. K. Hsu, Y. Q. Zhu et al., "Enhanced magnetic coercivities in Fe nanowires," Applied Physics Letters, vol. 75, no. 21, pp. 3363-3365, 1999.

[48] R. S. Lee, H. J. Kim, J. E. Fischer, A. Thess, and R. E. Smalley, "Conductivity enhancement in single-walled carbon nanotube bundles doped with K and Br," Nature, vol. 388, no. 6639, pp. 255-257, 1997.

[49] S. Ahn, Y. Kim, Y. Nam et al., "Magnetotransport in iodinedoped single-walled carbon nanotubes," Physical Review B, vol. 80, no. 16, Article ID 165426, 2009.

[50] S. S. Meysami, F. Dillon, A. A. Koós, Z. Aslam, and N. Grobert, "Aerosol-assisted chemical vapour deposition synthesis of multi-wall carbon nanotubes: I. Mapping the reactor," Carbon, vol. 58, pp. 151-158, 2013. 

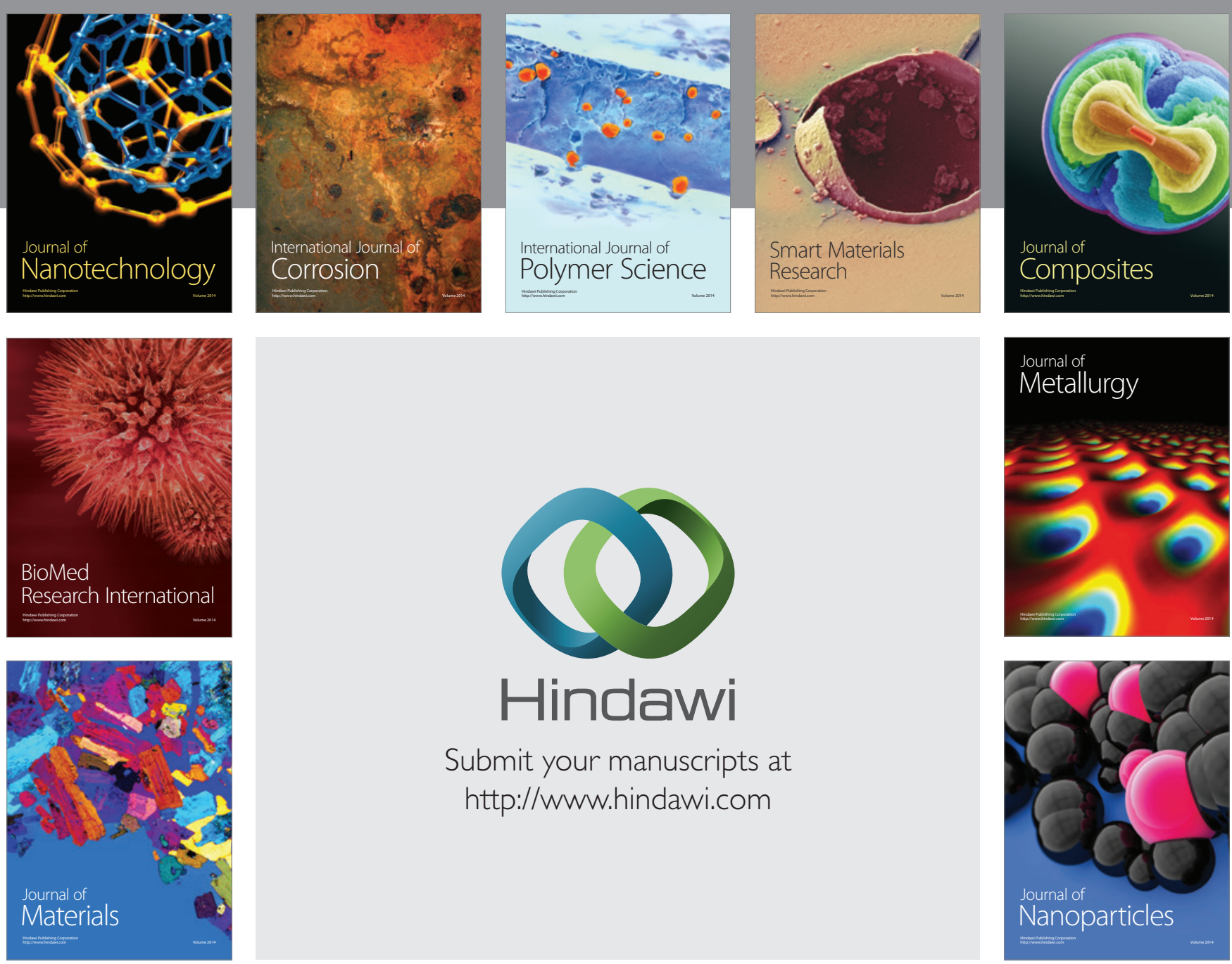

Submit your manuscripts at http://www.hindawi.com
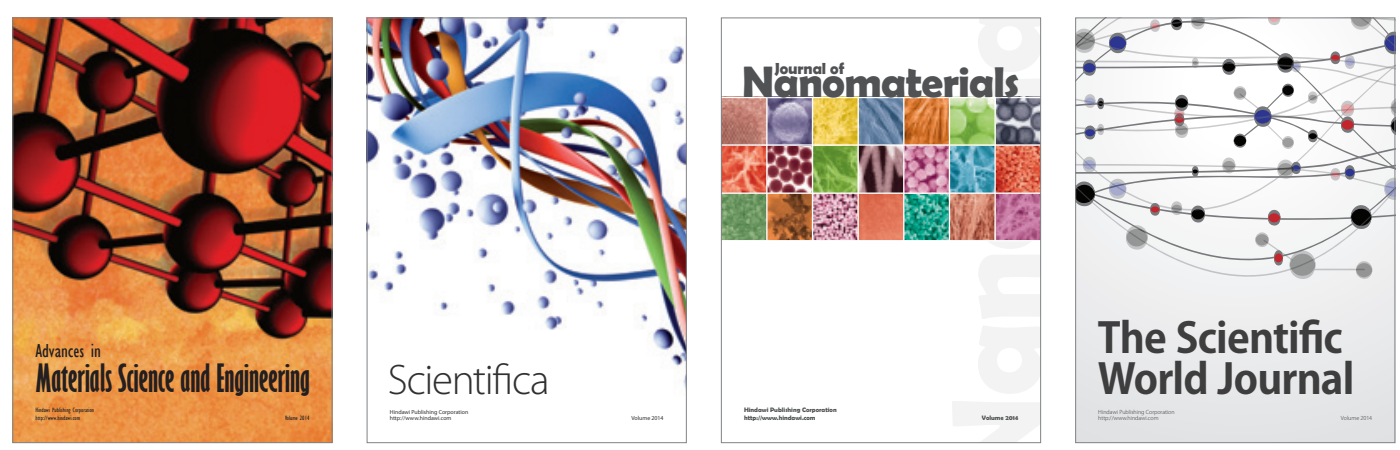

\section{The Scientific World Journal}
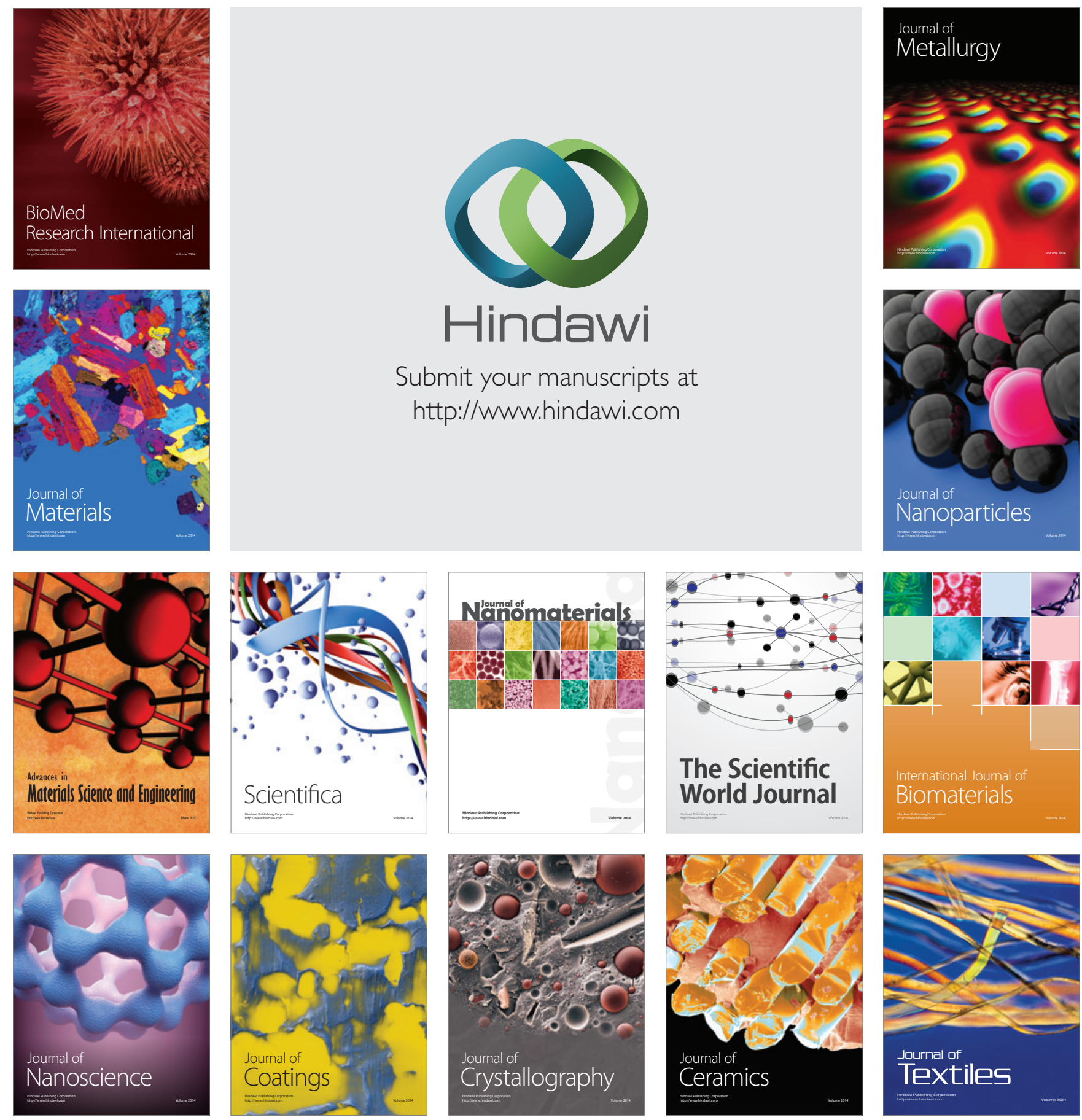